\title{
Utilization of By-Products and Wastes as Supplementary Cementitious Materials in Structural Mortar for Sustainable Construction
}

\author{
Shamir Sakir ${ }^{1}\left(\mathbb{D}\right.$, Sudharshan N. Raman ${ }^{1,2}{ }^{\circledR}$, Md. Safiuddin ${ }^{3,4,5, *}$, A. B. M. Amrul Kaish ${ }^{1}(\mathbb{C}$ \\ and Azrul A. Mutalib ${ }^{1}$ \\ 1 Department of Civil Engineering, Faculty of Engineering and Built Environment, \\ Universiti Kebangsaan Malaysia, 43600 UKM Bangi, Selangor, Malaysia; shamir@siswa.ukm.edu.my (S.S.); \\ snraman@ukm.edu.my (S.N.R.); amrul.kaish@ukm.edu.my (A.B.M.A.K.); azrulaam@ukm.edu.my (A.A.M.) \\ 2 Department of Architecture and Built Environment, Faculty of Engineering and Built Environment, \\ Universiti Kebangsaan Malaysia, 43600 UKM Bangi, Selangor, Malaysia \\ 3 Angelo DelZotto School of Construction Management, George Brown College, 146 Kendal Avenue, \\ Toronto, ON M5T 2T9, Canada \\ 4 Department of Civil Engineering, Faculty of Engineering and Architectural Science, Ryerson University, \\ 350 Victoria Street, Toronto, ON M5B 2K3, Canada \\ 5 Department of Civil and Environmental Engineering, Faculty of Engineering, University of Windsor, \\ 401 Sunset Avenue, Windsor, ON N9B 3P4, Canada \\ * Correspondence: msafiuddin@georgebrown.ca; Tel.: +1-416-415-5000 x6692
}

Received: 4 February 2020; Accepted: 20 April 2020; Published: 9 May 2020

\begin{abstract}
Rapid growth in industrial development has raised the concern of proper disposal of the by-products generated in industries. Many of them may cause serious pollution to the air, land, and water if dumped in open landfills. Agricultural and municipal wastes also cause environmental issues if not managed properly. Besides, minimizing the carbon footprint has become a priority in every industry to slow down global warming and climate change effects. The use of supplementary cementitious materials (SCMs) obtained from agricultural, industrial, municipal, and natural sources can decrease a significant amount of fossil fuel burning by reducing cement production and contribute to proper waste management. Also, SCMs can enhance desirable material properties like flowability, strength, and durability. Such materials may play a big role to meet the need of modern time for resilient construction. The effective application of SCMs in cement-based materials requires a clear understanding of their physical and chemical characteristics. Researchers studied how the flowability, strength, and durability properties of structural mortar change with the replacement of cement with different SCMs. Various experiments were conducted to examine the behavior of structural mortar in extreme conditions (e.g., high temperature). Many scholars have attempted to improve its performance with various treatment techniques. This article is an attempt to bring all the major findings of the recent relevant studies together, identify research gaps in the current state of knowledge on the utilization of SCMs in structural mortar, and give several recommendations for further study. The available results from recent studies have been reviewed, analyzed, and summarized in this article. A collection of the updated experimental findings will encourage and ease the use of various by-products and wastes as SCMs in structural mortar for sustainable construction.
\end{abstract}

Keywords: by-product; cement; structural mortar; supplementary cementitious material (SCM); sustainability; waste 


\section{Introduction}

Every second, a rain forest with the size of 19 tennis courts vanishes, 1600 tons of ice melt in Greenland, a desert area of $78 \mathrm{~m}^{2}$ expands in China, and 720 tons of $\mathrm{CO}_{2}$ are emitted by fossil fuel combustion [1]. This is how industrial development affects Mother Nature. The cement production industry is one of the prominent industries of the world. The history of cement-based materials is as old as human civilization. The development of modern hydraulic cement began at the beginning of the industrial revolution to meet the requirements of stronger and more durable cementitious products, which can survive in wet and salty conditions. The cement production has hiked up at an increasing rate in the last century. In 2015, the global production of cement was 3 billion tons, which had a $6.3 \%$ annual growth rate [2,3]. The production of each metric ton of Portland cement requires about 4-5 GJ of energy [4,5]. Around $60-130 \mathrm{~kg}$ of fuel oil or its equivalent and about $110 \mathrm{KW}$-h of electricity are required to produce one metric ton of cement, depending on the cement type and the processes used [6]. Approximately, $800-1000 \mathrm{~kg}$ of $\mathrm{CO}_{2}$ emissions occur during the production of each ton of cement $[3,7,8]$. About $5 \%-8 \%$ of the global man-made emissions of $\mathrm{CO}_{2}$ is caused by cement production $[3,5,8-10]$. To reduce the risk and impact of global warming and climate change, the "Paris Agreement" was signed in 2016. In this agreement, 152 parties (collectively responsible for $84.64 \%$ of the global emissions of greenhouse gases) have agreed to pursue limiting the temperature increase to $1.5^{\circ} \mathrm{C}$ above the preindustrial levels $[11,12]$. The utilization of cementitious and/or pozzolanic by-products and wastes as partial cement replacement materials can be helpful in this perspective. Within the context of this paper, if a secondary outcome of a process has some market value, it is referred to as "by-product". If it does not have any market value and is usually disposed of, it is considered as "waste".

Many industrial processes generate a huge quantity of by-products. Agricultural and municipal operations also generate a vast quantity of wastes. The proper disposal of these materials is a big concern. As these materials possess cementitious and/or pozzolanic properties, they can be used as a partial replacement of cement in cementitious composites, thus decreasing the high production cost and environmental pollution associated with cement factories. Such supplementary cementitious materials (SCMs) can save a significant amount of cement and give specific properties to cementitious products that help to meet the requirements of modern construction.

Different SCMs have various chemical and physical properties; thus, they produce different impacts on cement-based materials. Moreover, the generation of a specific SCM depends on a specific industrial, agricultural, or municipal process. Therefore, various SCMs are available in different parts of the world. Besides, the desired properties of cement-based materials mostly depend on the socio-economic and environmental conditions. Some societies are focused on new buildings, while some others are focused on retrofitting. In some cases, the performance is the highest priority while controlling cost is the highest priority in some other cases. Coastal, polar, and desert areas need cementitious products of special properties for their structures. For these limiting conditions, it is difficult to find an appropriate SCM for a specific purpose and optimize its quantity for cement-based materials.

In the present study, the research question was, "how can we utilize SCMs obtained from industrial, agricultural, municipal, and natural sources to reduce the carbon footprint of the construction industry?" To find the answer, scholarly articles were searched through Web of Science, Google Scholar, and Science Direct databases. During the search, the following keywords were used: "SCM", "supplementary cementitious materials", "cement replacement", "mortar", "fly ash", "silica fume", "ground granulated blast-furnace slag", "palm oil fuel ash", "rice husk ash", "bottom ash", "volcanic ash", "limestone powder", "metakaolin", "glass powder", and their different combinations. From the search outcomes, only the recent experimental results on cement mortar were emphasized. The fiber-reinforced mortar was excluded from this study because of its different working mechanism and characteristics.

The use of more SCMs as a partial replacement of cement will decrease the cost of cementitious products, reduce the environmental pollution, and consume the agricultural and industrial by-products or wastes; thus, it will contribute to significant progress towards sustainable construction. The objective 
of the present study is to summarize the effects of the major SCMs on the key properties of structural mortar so that the experts can easily decide a suitable amount for their purpose.

\section{Structural Mortar}

Mortar is defined as "a mixture of finely divided hydraulic cementitious material, fine aggregate, and water" [13]. Papayianni et al. [14] have classified mortar in three basic types:

- floor covering mortar,

- rendering mortar, and

- structural mortar.

In the case of floor covering and rendering mortars, strength is not a major concern. In certain applications, mortar has a load-bearing role. When a mortar is expected to resist some external forces and provide strength, it is referred to as "structural mortar".

The strength-oriented application of mortar is rising day by day. The structural mortar is being used as:

- binding material in masonry work,

- concrete repair material,

- matrix of thin reinforced cementitious products or composite systems (e.g., ferrocement, fabric-reinforced cementitious matrix (FRCM), textile-reinforced mortar (TRM), etc.),

- concrete equivalent mortar in scientific studies, and

- ultra-high performance concrete.

Versatile applications of structural mortar require different fresh and hardened properties. In masonry work, the mortar should be adequately workable to allow proper placement of masonry units above it. Usually, a mortar strength lower than the masonry unit is recommended so that cracks would occur at the joints [15]. Unlike masonry work, concrete repair and thin reinforced cementitious products need higher flowability to ensure proper placement in narrow and/or congested spaces. The mortar strength directly influences the performance of the whole structure in such cases. Usually, a higher strength is desirable.

The strength requirements of structural mortar for different applications are given in Table 1. To achieve the desirable properties and find a suitable mixture design for structural mortar, SCMs can be very effective tools. The use of appropriate SCMs at a proper ratio can enhance both the fresh and hardened properties of structural mortar, resulting in cost-effective construction and better performance.

Table 1. Strength requirements of structural mortar.

\begin{tabular}{ccc}
\hline Purpose & Minimum Strength at 28 Days (MPa) & Reference \\
\hline Masonry work (ASTM Type M) & 17.2 & {$[15]$} \\
Structural repair (EN Class R3) & 25.0 & {$[16]$} \\
Concrete repair & 27.6 & {$[17]$} \\
Thin reinforced cementitious products & 35.0 & {$[18]$} \\
Structural repair (EN Class R4) & 45.0 & {$[16]$} \\
\hline
\end{tabular}

\section{Major SCMs}

The major SCMs obtained from different sources are briefly described in the following subsections. The chemical compositions and key physical properties of ordinary Portland cement (OPC) and different SCMs are given in Table 2. 
Table 2. Chemical compositions of common SCMs and OPC.

\begin{tabular}{|c|c|c|c|c|c|c|c|c|c|c|c|}
\hline $\begin{array}{l}\text { Chemical } \\
\text { Composition } \\
\text { (wt.\%) }\end{array}$ & $\mathrm{FA}^{1}$ & $\mathbf{B A}^{1}$ & $\mathrm{SF}^{1}$ & GGBS $^{1}$ & LP $^{1}$ & MK $^{1}$ & $\mathrm{VA}^{1}$ & POFA $^{1}$ & RHA $^{1}$ & WGP $^{1}$ & OPC $^{2}$ \\
\hline $\mathrm{SiO}_{2}$ & $36-65$ & $44-59$ & 85-99 & $28-41$ & $0-8$ & $49-69$ & $45-65$ & $47-69$ & $17-94$ & $56-81$ & $16-23$ \\
\hline $\mathrm{CaO}$ & $1-19$ & $1-17$ & $0-4$ & $37-50$ & $45-55$ & $0-2$ & $3-11$ & $4-12$ & $0-2$ & $5-11$ & $49-69$ \\
\hline $\mathrm{Al}_{2} \mathrm{O}_{3}$ & $17-29$ & $5-32$ & $0-6$ & $5-14$ & $0-3$ & $25-44$ & $11-18$ & $1-9$ & $0-3$ & $0-6$ & $4-7$ \\
\hline $\mathrm{Fe}_{2} \mathrm{O}_{3}$ & $4-31$ & $2-9$ & $0-3$ & $0-1$ & $0-2$ & $0-3$ & $1-13$ & $1-10$ & $0-2$ & $0-1$ & $2-7$ \\
\hline $\mathrm{MgO}$ & $0-7$ & $1-3$ & $0-5$ & $4-10$ & $0-7$ & $0-3$ & $1-9$ & $2-6$ & $0-1$ & $0-4$ & $0-5$ \\
\hline $\mathrm{SO}_{3}$ & $0-3$ & $0-2$ & $0-2$ & $0-3$ & $0-1$ & $0-1$ & $0-1$ & $0-3$ & $0-1$ & $0-1$ & $0-1$ \\
\hline $\mathrm{Na}_{2} \mathrm{O}$ & $0-2$ & $0-1$ & $0-2$ & $0-3$ & $0-1$ & $0-1$ & $3-4$ & $0-1$ & $0-1$ & $7-16$ & $0-1$ \\
\hline $\mathrm{K}_{2} \mathrm{O}$ & $0-3$ & $1-8$ & $0-2$ & $0-2$ & $0-1$ & $0-2$ & $1-6$ & $5-11$ & $0-5$ & $0-1$ & $0-1$ \\
\hline $\mathrm{P}_{2} \mathrm{O}_{5}$ & $0-2$ & $0-1$ & $0-1$ & - & - & $0-1$ & $0-1$ & $3-5$ & - & - & - \\
\hline $\mathrm{TiO}_{2}$ & $0-2$ & $0-3$ & - & $0-1$ & - & $0-1$ & $0-3$ & - & - & - & - \\
\hline LOI & $0-5$ & $1-13$ & $0-6$ & $1-2$ & $36-45$ & $0-4$ & $1-6$ & $1-21$ & $0-6$ & $0-12$ & - \\
\hline Sp. gravity & 2.26 & 2.64 & 2.24 & 2.88 & 2.72 & 2.51 & 2.66 & 2.42 & 2.16 & 2.50 & 3.15 \\
\hline Ref. & [19-30] & {$[31-38]$} & {$[20,23,39-47]$} & {$[7,48-54]$} & {$[41,46,55-62]$} & {$[43,58,63-67]$} & {$[60,62,68-71]$} & {$[38,72-77]$} & {$[78-83]$} & [84-88] & {$[20,40,50,51,55,72,89,90]$} \\
\hline
\end{tabular}

${ }^{1}$ FA = Fly Ash; SF = Silica Fume; CGBS = Cround Cranulated Blast-Furnace Slag; WGP = Waste Glass Powder; LP = Limestone Powder; MK = Metakaolin; POFA = Palm Oil Fuel Ash;

RHA = Rice Husk Ash; BA = Bottom Ash; VA = Volcanic Ash. ${ }^{2}$ Ordinary Portland cement complying with EN 197-1 (Cement Type I-42.5 R). 


\subsection{SCMs from Industrial Processes}

\subsubsection{Fly Ash}

Fly ash (FA), also known as "pulverized fuel ash", is a secondary product of coal combustion [91]. Coal-based thermal power plants generate the greatest amount of FA. China, India, and the USA collectively generate more than $75 \%$ of global production. In 2008 , the global production of FA was 777 million tons [92]. China produces about 600 million tons of FA every year, with a utilization rate of less than $70 \%$ [38]. The annual production in the USA is 52 million short tons, whereas the utilization rate is only 44.5\% [93]. The main ingredients of $\mathrm{FA}$ are $\mathrm{SiO}_{2}, \mathrm{Al}_{2} \mathrm{O}_{3}, \mathrm{Fe}_{2} \mathrm{O}_{3}$, and $\mathrm{CaO}$ (Table 2). It also contains heavy metals. The presence of heavy metals in FA depends on its source [94]. Coal FA exhibits negligible ecotoxicity, though it contains traceable amounts of $\mathrm{As}, \mathrm{Cr}, \mathrm{Cu}, \mathrm{Ni}$, and $\mathrm{Zn}$. That is why coal FA is not considered a hazardous waste according to the Resource Conservation and Recovery Act (RCRA), 42 USC 6901-6991, and the US Environmental Protection Agency (EPA). On the other hand, municipal waste FA is a hazardous waste because of its contents of $\mathrm{Pb}, \mathrm{Zn}$, dioxins, and furans that are carcinogenic to humans. The removal or stabilization of these heavy metals is essential prior to the utilization of municipal waste FA [95]. In most of the studies, FA improved the flow properties of mortar because of its spherical particles. The $\mathrm{SiO}_{2}$ content of FA contributes to the pozzolanic reaction in mortar. Having a much lower specific gravity than OPC, FA increases the volume of mortar mixture if replaced by weight-to-weight (w/w) basis. FA also showed its potential as a solid sorbent for $\mathrm{CO}_{2}$ capture [96].

\subsubsection{Bottom Ash}

Bottom ash (BA) is a by-product generated from the burning of coal, biomass, or solid wastes. Unlike FA, BA (from coal and biomass) consists of heavier particles and more heavy metals that deposit at the bottom of the furnace [34,97]. The leaching behavior of BA has been a concern. Many studies found alarming levels of heavy metals $(\mathrm{Cu}, \mathrm{Pb}, \mathrm{Zn}, \mathrm{Ni}$, Sr, etc.) leaching from BA. Usually, the acidic $\mathrm{pH}$ and the presence of liquid increase the extent of leaching $[34,98]$. The USA and the EU together produced about 18 million tons of coal BA annually in the last decade [37]. Spain produces 43,200 tons of biomass BA in its power plants per year [33]. The global production of coal BA was about 134 million tons in 2011. For municipal waste BA, the global production was 440 million tons in 2016 [95]. The utilization rate of BA is very low compared to other wastes. For coal BA, it is only $33 \%$ in the USA, compared to $55 \%$ for FA [32]. The remaining part is used in landfilling as a common disposal practice. BA may cause many issues, namely, respiratory diseases when it gets airborne by winds and groundwater contamination by leaching of heavy metals [99]. The main constituent minerals of BA are $\mathrm{SiO}_{2}, \mathrm{Al}_{2} \mathrm{O}_{3}$, and $\mathrm{CaO}$ (Table 2). The influence of $\mathrm{BA}$ on mortar properties depends on its origin (coal, biomass, municipal waste, etc.), particle size, and treatment process.

\subsubsection{Silica Fume}

Silica fume (SF) is a by-product of the production of silicon and ferrosilicon alloys in electric arc furnaces through the carbothermic reduction of quartz. In recent times, the estimated global production of SF is $1.5 \mathrm{Mt}$ per year [100]. SF mostly consists of $\mathrm{SiO}_{2}$ (Table 2). This high silica content ensures very good pozzolanic reaction. Almost every study showed an improved strength for the substitution of OPC by SF. Owing to its small particle size, the mortar flowability is often reduced by SF [101]. Like FA, the mortar volume increases by the w/w replacement of OPC by SF for its low specific gravity (Table 2).

\subsubsection{Ground Granulated Blast-Furnace Slag}

Ground granulated blast-furnace slag (GGBS) is a by-product of steel and/or iron production process [102]. In 2014, 7.2 million tons of blast-furnace slag was produced only in the USA; the domestic sale of granulated blast furnace slag was about $\$ 175$ million in the USA in that year [103]. China produces about 220 million tons of blast-furnace slag annually [104]. The global production of GGBS is 
about 300-360 million tons per year [105]. The most dominant minerals in GGBS are $\mathrm{CaO}$ and $\mathrm{SiO}_{2}$, followed by $\mathrm{MgO}$ and $\mathrm{Al}_{2} \mathrm{O}_{3}$ (Table 2). GGBS allows a relatively high replacement level of cement without compromising the strength of mortar due to its self-cementing properties [53].

\subsubsection{Limestone Powder}

Limestone is a widely used natural mineral. Most of the concrete aggregates come from the crushing of limestone. This process generates fines called limestone powder (LP) that cannot be used as aggregate to produce concrete. About $20 \%$ of the limestone production is such powder, which is considered a by-product from the production of aggregate for concrete [41]. In 2014, 829 million metric tons of limestone aggregate were used only in the USA [106]. Unlike the other SCMs discussed in this article, $\mathrm{LP}$ contains only a small amount of $\mathrm{SiO}_{2}$, but it is rich in $\mathrm{CaO}$ (Table 2). Usually, its loss on ignition (LOI) is much higher than that of the other $\mathrm{SCMs}$. Lacking $\mathrm{SiO}_{2}$, $\mathrm{LP}$ does not react as a pozzolan. It affects mortar property as a filler and dilution material and acts as a nucleation site for cement hydration $[41,107]$. Some researchers see the potential of LP in reducing the carbon footprint of cementitious products by $15 \%$ [107].

\subsection{SCMs from Natural Sources}

\subsubsection{Metakaolin}

The raw material for porcelain manufacture is known as china clay or kaolin. It is a type of stone which is rich in kaolinite. Metakaolin (MK) is a dehydroxylated form of the clay mineral kaolinite. Purified kaolin clay is calcined at a temperature of $650-900{ }^{\circ} \mathrm{C}$ to break down crystalline structure and drive off water from it [66]. The production of 1 ton of MK requires $2.95 \mathrm{GJ}$ of energy and releases $175 \mathrm{~kg}$ of $\mathrm{CO}_{2}$ [65]. These values are $74 \%$ and $27 \%$ of those of the cement production process, respectively. Having a high specific surface area or surface fineness and irregular structure, MK raises the water demand of cementitious material for a given flowability. The calcination method determines the shape of MK particles. Smooth surface particles are produced through flash calcination [65]. MK mainly contains $\mathrm{SiO}_{2}$ and $\mathrm{Al}_{2} \mathrm{O}_{3}$ (Table 2). Owing to these minerals, MK shows an excellent pozzolanic effect on cement hydration in cementitious composites. Almost every study reported a positive impact of MK on the strength of mortar.

\subsubsection{Volcanic Ash}

During volcanic eruptions, volcanic ash (VA) is formed by shattering of solid rock and separation of magma. The explosion during an eruption tears the magma and solid rock surrounding the volcanic vent into particles from clay to sand size. The particle size of VA decreases exponentially with the distance from the volcano [108]. Ancient Romans were the pioneers in using VA to make durable mortars for salty environments [62,109]. Usually, VA consists of volcanic glass, minerals or crystals, and other rock fragments (lithics) [108]. Italy is the largest producer of VA. The other major VA producing countries are Chile, Canada, Spain, Turkey, and the USA. VA is rich in $\mathrm{SiO}_{2}$ and $\mathrm{Al}_{2} \mathrm{O}_{3}$ (Table 2). It satisfies the criteria for Class $\mathrm{N}$ pozzolana $[68,69]$.

\subsection{SCMs from Agricultural Wastes}

\subsubsection{Palm Oil Fuel Ash}

Palm oil is one of the most important agricultural products in Malaysia, Indonesia, Thailand, and some other countries. Palm oil residues are used as fuel. This waste goes through the burning operation at $800-1000{ }^{\circ} \mathrm{C}$ for electricity generation. In 2010, Malaysia, Indonesia, and Thailand together produced approximately 7 million tons of ash in palm oil mills [110]. This ash is known as palm oil fuel ash (POFA). An appreciable content of $\mathrm{SiO}_{2}$ (Table 2) gives the pozzolanic property to POFA. The raw POFA particles are porous and large, containing a considerable amount of unburnt carbon. The use of 
POFA without prior treatment may cause some undesirable effects on the properties of cement-based materials $[76,111]$. Treated POFA can save as much as $80 \%$ of OPC without compromising the key properties of mortar [74].

\subsubsection{Rice Husk Ash}

China, India, Indonesia, and Bangladesh are the top rice producers in the world. The global rice production in 2016 was 716 million metric tons [112]. This amount of rice generated about 150 million metric tons of rice husk. Rice husk is used as a fuel in the boiler for power generation. The ash obtained from the burning of rice husks is known as rice husk ash (RHA). Approximately, 30 million metric tons of RHA can be produced from the present global rice production $[83,113]$. The physical and chemical properties of RHA vary depending on the burning process of rice husks. A burning temperature lower than $500{ }^{\circ} \mathrm{C}$ leaves an objectionable amount of unburnt carbon in the resulting ash $[78,83]$. Again, the silica may form inactive crystals if the temperature is higher than $800^{\circ} \mathrm{C}$. Moreover, the burning duration should be long enough to burn out all cellulose contained in rice husks and leave white or grey ash [113]. A temperature of $550-700{ }^{\circ} \mathrm{C}$ for $1 \mathrm{~h}$, followed by grinding is recommended for high-quality RHA [78]. A proper burning and grinding of rice husks can produce RHA with similar chemical and mineralogical compositions as SF. Alike SF, RHA mainly consists of $\mathrm{SiO}_{2}$ (Table 2). With a much lower specific gravity than OPC, RHA increases the volume of cementitious mixture if used as a partial replacement of cement on $\mathrm{w} / \mathrm{w}$ basis.

\subsection{SCMs from Solid Wastes}

Glass is one of the world's most common commodities. About 11.5 million tons of waste glass are generated annually in the USA, with a recycling rate of only $27 \%$ [114]. About 3 million tons of glass were produced in 2011 only in Brazil [85]. In 2001, the amount of nonrecyclable waste glass that went into landfills in the UK was about 1.65 million tons [115]. In 2015, Korea alone produced 40,000 tons of waste of Liquid Crystal Display (LCD) glass panels [116]. Although waste glass powder (WGP) can be categorized as a pozzolanic-cementitious material according to ASTM C618, the risk of alkali-silica reaction (ASR) has limited its use in cement-based materials [84,115,117]. WGP is enriched in $\mathrm{SiO}_{2}$ content; $\mathrm{CaO}$ quantity is also significant (Table 2). Unlike other common SCMs, a high content of $\mathrm{Na}_{2} \mathrm{O}$ is present in WGP. This $\mathrm{Na}_{2} \mathrm{O}$ may form water-absorbing $\mathrm{N}-\mathrm{H}-\mathrm{S}$ gel in the hardened cement-based products, causing expansion leading to cracking and spalling of hydrated cementitious compound. The use of low calcium SCM along with WGP of smaller particles can minimize the chance of ASR [84,118]. If there is not enough $\mathrm{SiO}_{2}$ left after the pozzolanic reaction, ASR cannot occur.

\section{Principal Functioning Mechanisms of SCMs}

The effects of SCMs are governed by the laws of physics, chemistry, and thermodynamics. Dodson [119] described that SCMs influence the properties of cement-based materials by:

- dispersing cement particles,

- modifying the kinetics of the hydration of cement,

- reacting with the secondary product of cement hydration, and

- physically filling the pore spaces in cement paste.

Practically cement paste is a yield stress fluid [120]. The viscosity of binder paste generates viscous stress, resisting the mortar flow. Different sizes of particles move at different rates, causing shear stresses by collision, friction, and interlocking. The interaction between binder paste and aggregate particles also generates stress. Lu et al. [121] have identified the following sources of resistance against the mortar flow:

- the yield stress of binder paste,

- the viscous stress of binder paste, 
- the interaction between the binder paste and aggregates, and

- the stress resulting from the movement of aggregates.

Figure 1 illustrates the active forces against the flow of mortar, as illustrated by Lu et al. [121].

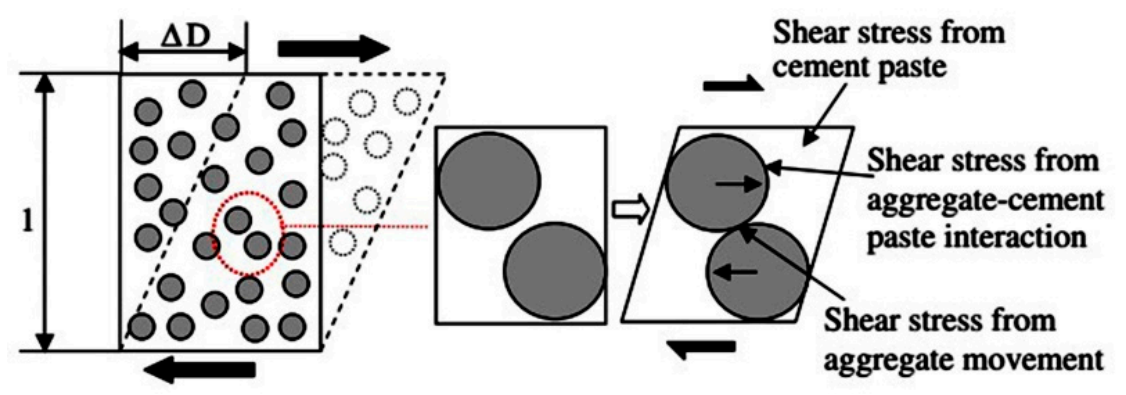

Figure 1. Forces against the mortar flow as portrayed by Lu et al. [121].

Roussel et al. [120] have identified four main forces that determine the rheological nature of the binder paste:

- $\quad$ surface forces (or colloidal interactions),

- Brownian forces,

- hydrodynamic forces, and

- $\quad$ various contact forces between particles.

The fresh properties of mortar are basically affected by the size, shape, and surface area of its solid ingredients. Smooth and spherical particles usually improve the flow properties of mortar by ball-bearing effect [29]. In contrast, the smaller size and higher surface area of particles usually reduce the flowability of mortar mixture due to the increased water demand for wetness; also, angular and porous particles absorb some mixing water and thus decrease the flowability of mortar mixture [122]. The static stability of a freshly mixed cement-based material depends on the yield stress (fluidity) and the difference between the densities of binder paste and aggregates [123]. On the other hand, the dynamic stability of a cementitious mixture mostly depends on its viscosity [124]. In close distance, van der Waals force is the most dominant force among the particles in binder paste [125]. Electrostatic repulsion also originates from the adsorbed ions at the particle surface [126]. A smaller portion of cement particles may have Brownian motion and diffuse through the liquid. Usually, most SCM particles are far smaller than cement particles. The substitution of a portion of cement by such particles may significantly increase the Brownian motion, resulting in higher diffusion, reduced bleeding, and more stable suspension [120].

Brownian motion causes the diffusion of cement particles through the liquid. In the course, the particles may come close enough to develop the van der Waals force of attraction. Usually, Brownian motion and electrostatic repulsion are not enough alone or even together to overcome van der Waals force. The addition of water-reducing admixture may increase the distance among particles by getting adsorbed on the surface of cement particles and causing electrostatic repulsion and steric hindrance, thus reducing the magnitude of van der Waals force [120]. These interparticle forces are influenced by the hydration process of cementitious ingredients, material properties, mixture proportions, mixing and placement procedures, elapsed time, ambient temperature, relative humidity, etc. [52].

SCM particles decrease the porosity and increase the strength by filling up the gaps between cement particles. This effect is termed as "filler effect" [127]. The surface of SCM particles affects the hydration in two ways. Providing additional nucleation sites, SCM particles help the hydration products to precipitate [128]. In addition, calcium ions get adsorbed on the SCM surface, resulting in a lower $\mathrm{Ca} / \mathrm{Si}$ ratio, which leads to the stability of the initial C-S-H (calcium-silicate-hydrate) layer in cement-based materials [129]. 
Effective water-to-cement $(\mathrm{w} / \mathrm{c})$ ratio directly affects the porosity and strength of mortar. The lower ratio gives more strength and less porosity. Partial cement replacement by any SCM will raise the effective w/c ratio at a constant water-to-binder $(\mathrm{w} / \mathrm{b})$ ratio. This phenomenon is called "dilution effect". The dilution effect helps the long-term hydration reaction of cement although the degree of hydration of binder may be relatively low. That is why the substitution of cement by SCM above a certain level may harm the mechanical properties of mortar [56,130]. At a constant $\mathrm{w} / \mathrm{c}$ ratio, the fineness of binder materials controls the porosity and pore size distribution in cement-based materials such as mortar [131].

The "pozzolanic effect" of SCM is to react with the secondary product, $\mathrm{Ca}(\mathrm{OH})_{2}$ (calcium hydroxide, also known as portlandite), of cement hydration to form additional C-S-H gel (secondary C-S-H). During the pozzolanic reaction, the longer silicate chains are formed as the Ca:Si molar ratio of $\mathrm{C}-\mathrm{S}-\mathrm{H}$ drops [132]. This secondary C-S-H reduces the porosity in bulk cement paste and improves the interfacial bond between aggregate particles, and thus increases the strength, density, and ion diffusion resistance of mortar; pozzolanic activity results in a lower $\mathrm{Ca}(\mathrm{OH})_{2}$ concentration, causing a higher $\mathrm{Ca}^{2+}$ dissolution rate from the cement particles [41,129]. It is possible that the smallest basic particles of C-S-H gel ( $\leq$ size $4.2 \mathrm{~nm}$ ) deposit on the walls of large gel pores, which have a diameter of 3-12 nm. Such deposition causes a partial or complete blockage of diffusion path, reducing the porosity in hardened cement compound [129]. Figure 2 shows an illustration of this phenomenon.

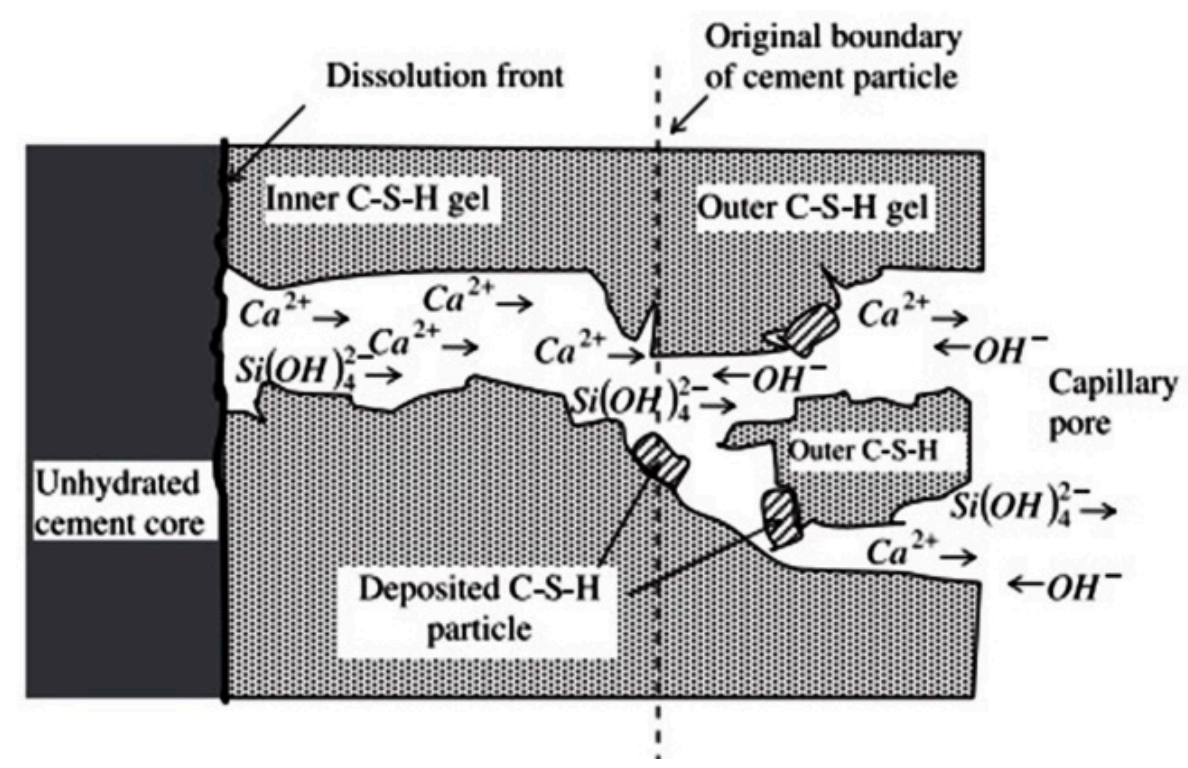

Figure 2. Deposition mechanism of C-S-H particles [129].

Excessive secondary hydration may have a detrimental effect on the corrosion resistance of cement-based materials [41]. $\mathrm{Ca}(\mathrm{OH})_{2}$ provides a buffer for the pore solution, maintaining a minimum $\mathrm{pH}$ level of 12.6. Extreme pozzolanic activity may damage the $\mathrm{pH}$ buffer, resulting in a drop of $\mathrm{pH}$ to a level at which the embedded steel may start acting as an electrode and become corroded [131].

\section{Effects of SCMs on the Properties of Structural Mortar}

The effects of various SCMs on the flowability, strength, and durability are discussed in the following subsections. The influences of SCMs on these mortar properties are summarized in Tables 3 and 4 . The best results provided by prominent SCMs are given in Table 5 . 
Table 3. Effects of major SCMs on the flow and strength properties of mortar.

\begin{tabular}{|c|c|c|c|c|c|c|}
\hline \multirow[b]{2}{*}{ SCM } & \multicolumn{3}{|c|}{ Flowability } & \multicolumn{3}{|c|}{ Strength } \\
\hline & Effect & $\begin{array}{c}\text { Replacement Ratio } \\
{[\% \mathrm{w} / \mathrm{w}]}\end{array}$ & Ref. & Effect & $\begin{array}{c}\text { Replacement } \\
\text { Ratio } \\
{[\% \mathrm{w} / \mathrm{w}]}\end{array}$ & Ref. \\
\hline \multirow{2}{*}{ FA } & $\Delta$ & $5-30$ & {$[20,24,25,29,56,89]$} & $\Delta$ & $0-40$ & {$[22,24,25,43,133,134]$} \\
\hline & $\boldsymbol{v}$ & $25-30$ & [26] & $\boldsymbol{v}$ & $10-70$ & {$[22,24,26,28-30,43,89]$} \\
\hline \multirow{2}{*}{ SF } & $\Delta$ & 7.3 & [135] & $\Delta$ & $5-25$ & {$[26,39,46,135-137]$} \\
\hline & $\mathbf{v}$ & $5-20$ & {$[26,46,101]$} & $\mathbf{v}$ & $5-20$ & [39] \\
\hline \multirow[t]{2}{*}{ GGBS } & $\Delta$ & $10-30$ & [49] & $\Delta$ & $\begin{array}{l}20-60 \\
10-70\end{array}$ & {$[49,50]$} \\
\hline & & & & 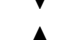 & $\begin{array}{l}10-/ 0 \\
5-25\end{array}$ & {$\left[\begin{array}{l}{[49,03]} \\
{[20,87]}\end{array}\right.$} \\
\hline WGP & $\mathbf{v}$ & $5-25$ & [20] & $\mathrm{v}$ & $5-40$ & {$[84,85,87,88]$} \\
\hline \multirow{2}{*}{ LP } & $\Delta$ & $5-70$ & {$[25,46,56,138,139]$} & $\Delta$ & $2.4-15$ & {$[55,138-140]$} \\
\hline & $\mathbf{v}$ & $20-30$ & [138] & $\mathbf{v}$ & $5-50$ & {$[41,46,59,62]$} \\
\hline \multirow{2}{*}{ MK } & $\nabla$ & $12.5-25$ & {$[64,65]$} & $\Delta$ & $5-20$ & {$[43,64,67,141-144]$} \\
\hline & & & & $\mathbf{v}$ & $5-15$ & [145] \\
\hline \multirow{2}{*}{ POFA } & $\Delta$ & $5-50$ & [72] & $\Delta$ & $10-80$ & {$[74,77]$} \\
\hline & $\mathbf{v}$ & $10-30$ & {$[76,111]$} & $\mathbf{v}$ & $10-30$ & {$[38,76,111]$} \\
\hline \multirow{2}{*}{ RHA } & $\mathbf{v}$ & $5-20$ & [113] & $\Delta$ & $5-25$ & {$[78,83]$} \\
\hline & & & & & $\begin{array}{l}5-30 \\
5-33\end{array}$ & {$[79,80,83,113]$} \\
\hline BA & $\Delta$ & $9-41$ & {$[32,37]$} & v & $\begin{array}{l}0-33 \\
6-41\end{array}$ & {$[32-35,37,38,97,146]$} \\
\hline \multirow{2}{*}{ VA } & - & - & - & $\Delta$ & $20-30$ & [60] \\
\hline & & & & $\mathbf{v}$ & $20-50$ & {$[60,62,68-71]$} \\
\hline
\end{tabular}

Note: " $\mathbf{\Delta}$ " indicates an increase and " $\mathbf{\nabla}$ " indicates a decrease in the behavior.

Table 4. Effects of major SCMs on the durability properties of mortar.

\begin{tabular}{|c|c|c|c|c|c|c|c|c|c|c|c|c|}
\hline \multirow[b]{2}{*}{ SCM } & \multicolumn{2}{|c|}{$\begin{array}{l}\text { Carbonation } \\
\text { Resistance }\end{array}$} & \multicolumn{2}{|c|}{$\begin{array}{c}\text { Acid } \\
\text { Resistance }\end{array}$} & \multicolumn{2}{|c|}{$\begin{array}{c}\text { ASR } \\
\text { Resistance }\end{array}$} & \multicolumn{2}{|c|}{ Sulphate Resistance } & \multicolumn{2}{|c|}{$\begin{array}{l}\text { Chloride } \\
\text { Resistance }\end{array}$} & \multicolumn{2}{|c|}{$\begin{array}{l}\text { Freezing and } \\
\text { Thawing Resistance }\end{array}$} \\
\hline & Effect & Ref. & Effect & Ref. & Effect & Ref. & Effect & Ref. & Effect & Ref. & Effect & Ref. \\
\hline FA & - & - & - & - & $\Delta$ & {$[147]$} & $\Delta$ & {$[43,148,149]$} & $\Delta$ & [29] & $\Delta$ & [43] \\
\hline SF & $\Delta$ & $\begin{array}{c}{[150]} \\
{[84]}\end{array}$ & $\Delta$ & [151] & $\Delta$ & [152] & $\Delta$ & {$[43,84,148,152]$} & $\Delta$ & $\begin{array}{l}{[43,} \\
84]\end{array}$ & $\Delta$ & {$[43]$} \\
\hline GGBS & - & - & - & - & - & - & $\Delta$ & {$[148,153]$} & $\Delta$ & [154] & - & - \\
\hline WGP & $\mathbf{v}$ & [84] & - & - & $\Delta$ & $\begin{array}{l}{[84,} \\
152]\end{array}$ & $\Delta$ & {$[84,152]$} & $\Delta$ & [84] & - & - \\
\hline LP & $\nabla$ & [58] & - & - & - & - & $\begin{array}{c}\text { No effect } \\
\boldsymbol{\nabla}\end{array}$ & $\begin{array}{c}{[148,149]} \\
{[155]}\end{array}$ & - & - & - & - \\
\hline MK & $\boldsymbol{\nabla}$ & [58] & $\Delta$ & [151] & $\Delta$ & [156] & $\Delta$ & {$[43,148,156]$} & $\begin{array}{l}\Delta \\
\mathbf{v}\end{array}$ & $\begin{array}{l}{[43} \\
151] \\
{[67]}\end{array}$ & $\Delta$ & [64] \\
\hline POFA & - & - & - & - & - & - & $\Delta$ & [157] & - & - & - & - \\
\hline RHA & - & - & $\Delta$ & [81] & - & - & $\Delta$ & [158] & $\Delta$ & $\begin{array}{l}80, \\
90]\end{array}$ & - & - \\
\hline BA & $\nabla$ & [146] & - & - & $\hat{\Delta}$ & $\begin{array}{c}{[146]} \\
{[35]}\end{array}$ & $\Delta$ & [146] & - & - & $\boldsymbol{v}$ & [146] \\
\hline VA & - & - & - & - & $\Delta$ & [69] & - & - & $\Delta$ & [70] & - & - \\
\hline
\end{tabular}

Note: " $\mathbf{\Delta}$ " indicates an increase and " $\mathbf{\nabla}$ " indicates a decrease in the behavior.

Table 5. Best performance of prominent SCMs.

\begin{tabular}{ccccccccc}
\hline & \multicolumn{3}{c}{ Flow Spread } & \multicolumn{5}{c}{ Compressive Strength (28 days) } \\
\hline SCM & $\begin{array}{c}\text { Value } \\
{[\mathbf{m m}]}\end{array}$ & $\begin{array}{c}\text { Replacement Ratio } \\
{[\% \mathbf{w} / \mathbf{w}]}\end{array}$ & $\begin{array}{c}\mathbf{w / b} \text { Ratio } \\
\mathbf{( \%} \mathbf{~ w / w )}\end{array}$ & Ref. & $\begin{array}{c}\text { Value } \\
{[\mathbf{M P a}]}\end{array}$ & $\begin{array}{c}\text { Replacement Ratio } \\
{[\% \mathbf{w} / \mathbf{w}]}\end{array}$ & $\begin{array}{c}\mathbf{w} / \mathbf{b} \text { Ratio } \\
\mathbf{\%} \mathbf{w} \mathbf{w} / \mathbf{w})\end{array}$ & Ref. \\
\hline FA & 241 & 25.0 & 0.43 & {$[26]$} & 122 & 35.0 & 0.21 & {$[133]$} \\
SF & 369 & 7.3 & 0.46 & {$[135]$} & 118 & 7.3 & 0.20 & {$[135]$} \\
GGBS & 232 & 30.0 & 0.70 & {$[49]$} & 57 & 50.0 & - & {$[50]$} \\
WGP & 216 & 5.0 & 0.40 & {$[20]$} & 56 & 20.0 & 0.35 & {$[87]$} \\
LP & 445 & 30.0 & 0.34 & {$[139]$} & 69 & 15.0 & 0.35 & {$[25]$} \\
MK & - & - & - & - & 120 & 20.0 & 0.30 & {$[67]$} \\
POFA & 310 & 5.0 & 0.35 & {$[72]$} & 75 & 10.0 & 0.35 & {$[111]$} \\
RHA & 255 & 20.0 & 0.84 & {$[113]$} & 70 & 20.0 & 0.40 & {$[83]$} \\
BA & 230 & 21.0 & 0.38 & {$[37]$} & 82 & 5.0 & 0.52 & {$[35]$} \\
VA & - & - & - & - & 45 & 10.0 & 0.40 & {$[68]$} \\
\hline
\end{tabular}




\subsection{Fly Ash (FA)}

\subsubsection{Effects on Flowability}

FA particles are relatively smoother and spherical compared to cement particles. The ball-bearing effect of the smooth spherical particles of FA usually improves the flow properties of mortar [29]. The flowability of mortar increases with the increased FA content up to 30\% [25]. The mortar mixture with $30 \%$ FA exhibited a similar flowability with $42 \%$ less superplasticizer (SP) as compared with the mortar mixture without FA [89]. A similar effect was observed in the studies of Parghi and Alam [20] as well as Silva and de Brito [56]. Along with the drop in SP demand, the optimum dosage of SP also decreases as the FA content rises [30]. Even at 70\% replacement of cement, for the mortar prepared with $0.40 \mathrm{w} / \mathrm{b}$ ratio, a flow spread of $194 \mathrm{~mm}$ was recorded, when examined according to ASTM C1437 [159]; this flow value was $45 \%$ higher than that of the control mixture [24]. FA was also successfully used to prepare self-compacting mortar. In one study, the self-compacting mortars including $25 \%-40 \%$ FA exhibited 11.0-14.8 s V-funnel flow time (measured using a mini V-funnel modified for testing mortar instead of concrete) and $241-250 \mathrm{~mm}$ flow spread, compared to the $7.1 \mathrm{~s}$ flow time and $247 \mathrm{~mm}$ flow spread of the control mortar [26].

The fluidity of a mortar mixture is highly influenced by the particle size of FA. Smaller FA particles give a better flow. The mortar mixture including 5\% ultra-fine FA (mean size $3.4 \mu \mathrm{m}$ ) as a partial replacement of cement provided a flow spread of $140 \mathrm{~mm}$, which is $4.5 \%$ higher than the $135 \mathrm{~mm}$ flow spread of the control mixture; a $40 \%$ replacement of cement by normal-size FA was required to achieve the same level of flowability; at a 15\% replacement of cement by this ultra-fine FA, a flow spread of $160 \mathrm{~mm}$ was achieved; all the mortar mixtures had a constant water content of $160 \mathrm{~kg} / \mathrm{m}^{3}$ [24]. The mortar mixture with $20 \%$ and $40 \%$ FA microsphere (mean size $2.6 \mu \mathrm{m}$ ) gave a flow spread (measured using a mini-slump cone) of $225 \mathrm{~mm}$ and $247.5 \mathrm{~mm}$, respectively, at a w/b ratio of 0.49 ; this is $7.14 \%$ and $17.8 \%$ higher than the flow spread of OPC mortar [133]. As smaller particles experience more Brownian motion, they result in a better flow due to enhanced dispersion of mortar particles. Despite all the above-mentioned positive effects, high cement replacement by FA (more than $30 \%$ ) at a relatively high $\mathrm{w} / \mathrm{b}$ ratio may cause segregation and bleeding problems in mortar mixtures [64].

\subsubsection{Effects on Strength}

Due to the dilution effect and slow pozzolanic reaction, FA has an adverse effect on the early-age strength of mortar. The early-age strength goes down for a cement replacement by FA in the range of $10 \%-70 \%$ [24,26,28-30,43,89,160]. The use of $40 \%$ FA causes a $34 \%$ decrease in the 28 -day tensile strength of mortar [26]. The higher the amount of FA, the lower is the early-age strength [26,29]. The strength gap between the mortar with OPC alone and the mortar with binary FA-OPC binder decreases with age. In some studies, it took 90 days to show a similar or better strength compared to the control mortar $[28,29]$. Other investigations have shown that it took a longer time to gain a similar strength [26,43]. In the study of Mardani-Aghabaglou et al. [43], the mortar with $10 \%$ FA took 200 days to reach the strength of the control mortar; at 300 days, it achieved $5 \%$ higher strength. In contradiction with the general trend, Antoni et al. [25] have reported $1.5 \%-4.5 \%$ more compressive strength for $10 \%-30 \%$ FA at the w/b ratio of 0.35 .

The particle size of FA plays a significant role in the strength gain of mortar. The mortar with $8 \%$ ultra-fine FA (mean size $3.4 \mu \mathrm{m}$ ) as a partial replacement of cement provided $23 \%$ higher compressive strength than the control mortar; it showed a better strength up to $15 \%$ cement replacement [24]. The use of FA microsphere (mean size $2.6 \mu \mathrm{m}$ ) produced 116.2 and $121.9 \mathrm{MPa}$ compressive strength at $20 \%$ and $40 \%$ cement replacement in mortar mixture, respectively, compared to the $96.2 \mathrm{MPa}$ compressive strength of OPC mortar $[133,135]$. A w/c ratio lower than 0.27 is required for such high strengths. Figure 3 shows the detailed results. Using FA microsphere causes a drop in the optimum $\mathrm{w} / \mathrm{c}$ ratio. It results in more strength at the same flowability, or otherwise, more flowability at the same strength [133]. Due to the lack of lime, nano-FA (mean size $0.04 \mu \mathrm{m}$ ) cannot produce a better strength 
at 7 days. Accompanied by nano-lime, it can show $14.81 \%$ more strength at the age of 7 days [134]. Smaller particles have a better filler effect. In addition, with more surface area, smaller particles offer higher reactivity during secondary hydration. As a result, these effects contribute to increase the strength of mortar.

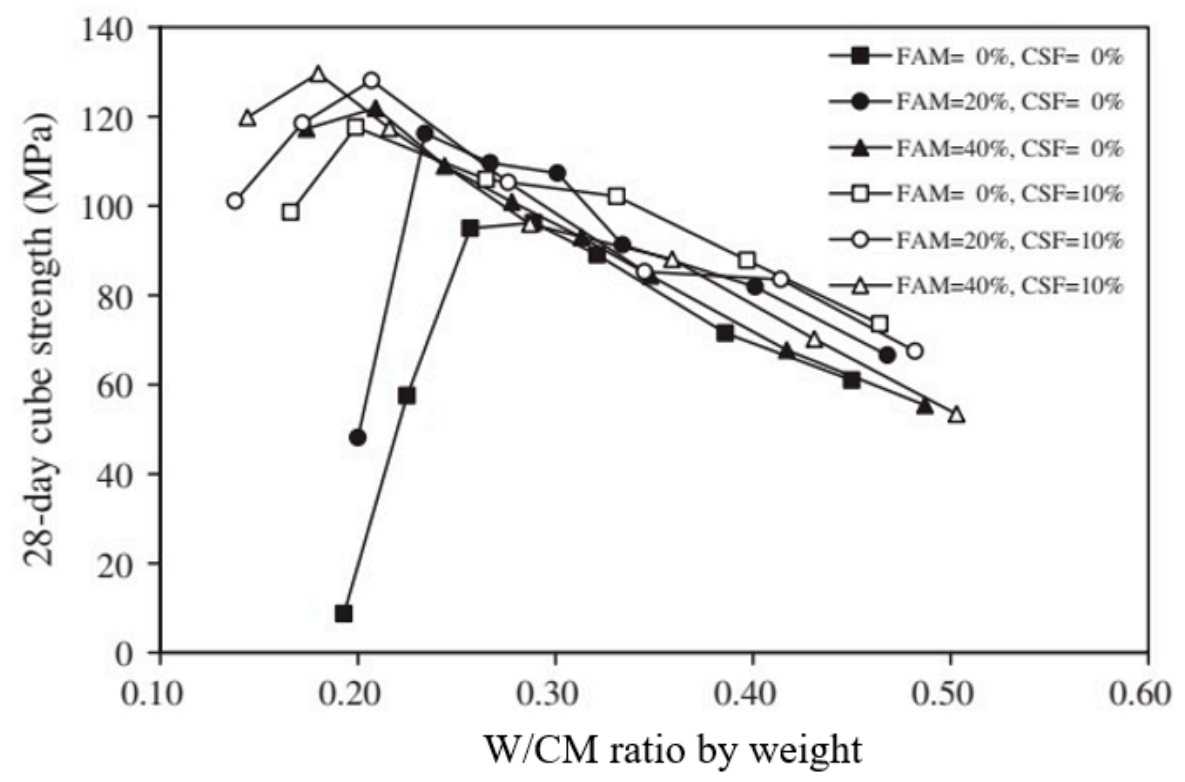

Figure 3. Effects of FA microsphere (FAM) and condensed SF (CSF) on the mortar strength at different $\mathrm{w} / \mathrm{cm}$ or $\mathrm{w} / \mathrm{b}$ ratios [135]. [W/CM ratio $=$ water-to-cementitious material ratio].

\subsubsection{Effects on Durability and Other Properties}

FA improves the sulphate resistance of mortar marginally. The mortar samples with $10 \%$ FA showed $0.1 \%$ expansion in 180 days [43]. Moreover, the mortar samples prepared with moderate $\mathrm{C}_{3} \mathrm{~A}$ ( $8 \%-9 \%$ ) cement, $4 \%-22 \%$ LP, and 15\% FA had less than $0.04 \%$ expansion after 12 months [148]. It was also reported that Class F FA can improve the sulphate resistance of mortar at a temperature as low as $5{ }^{\circ} \mathrm{C}$ [149]. However, it should be mentioned that the pozzolanic activity of FA forms both needle-like and ball ettringites. The needle-like ettringite formation has an expansive nature. This process may create micro-crack in the matrix and thus it could limit the sulphate resistance of mortar [43].

Figure 4 shows the compressive strength values of different mortars, with $20 \%-60 \%$ cement substitutions by FA, after exposure to high temperature. The mortars containing $20 \%-60 \%$ FA retained approximately $80 \%$ of their unheated $\left(27^{\circ} \mathrm{C}\right)$ strength up to $400{ }^{\circ} \mathrm{C}$. At $600{ }^{\circ} \mathrm{C}$ and $800{ }^{\circ} \mathrm{C}$, the strength loss is up to $45 \%$ and $80 \%$, respectively, for $60 \%$ FA. The mortar with $20 \%$ FA showed a better performance as compared with the mortars including $40 \%$ and $60 \%$ FA. At all temperatures, the mortar containing 20\% FA had a better strength than the control mortar, though the percentage of strength loss was almost the same. Thus, FA mortar is considered suitable for application in the cases with high fire risk [67]. FA also improves the resistance of mortar against ASR. The mortar samples containing $60 \%-80 \%$ coal combustion by-product ( $95 \%$ FA) had an ASR expansion of $0.058 \%-0.035 \%$ after 28 days immersion in $1 \mathrm{~N} \mathrm{NaOH}$ solution at $80^{\circ} \mathrm{C}$. In the same condition, the OPC mortar samples suffered $0.212 \%$ expansion [147].

Densifying the matrix, FA improves the transport properties of mortar. FA decreased the chloride permeability of mortar at all ages for $10 \%$ cement replacement and after 90 days for $20 \%$ cement replacement $[29,43]$. Similarly, almost two-fold and more than three-fold electrical resistivity values were recorded at 180 days for $10 \%$ and $20 \%$ FA, respectively [29]. Freezing and thawing behavior is highly influenced by the degree of saturation. That is why certain transport properties (e.g., water absorption, water permeability) can be considered as an indirect measure of freezing and thawing 
resistance. Same as the transport properties, the freezing and thawing resistance of mortar improves with the inclusion of FA. After 300 freeze-thaw cycles, 18\% of the compressive strength of $10 \%$ FA mortar was lost while $26 \%$ was lost for the mortar with no FA [43].

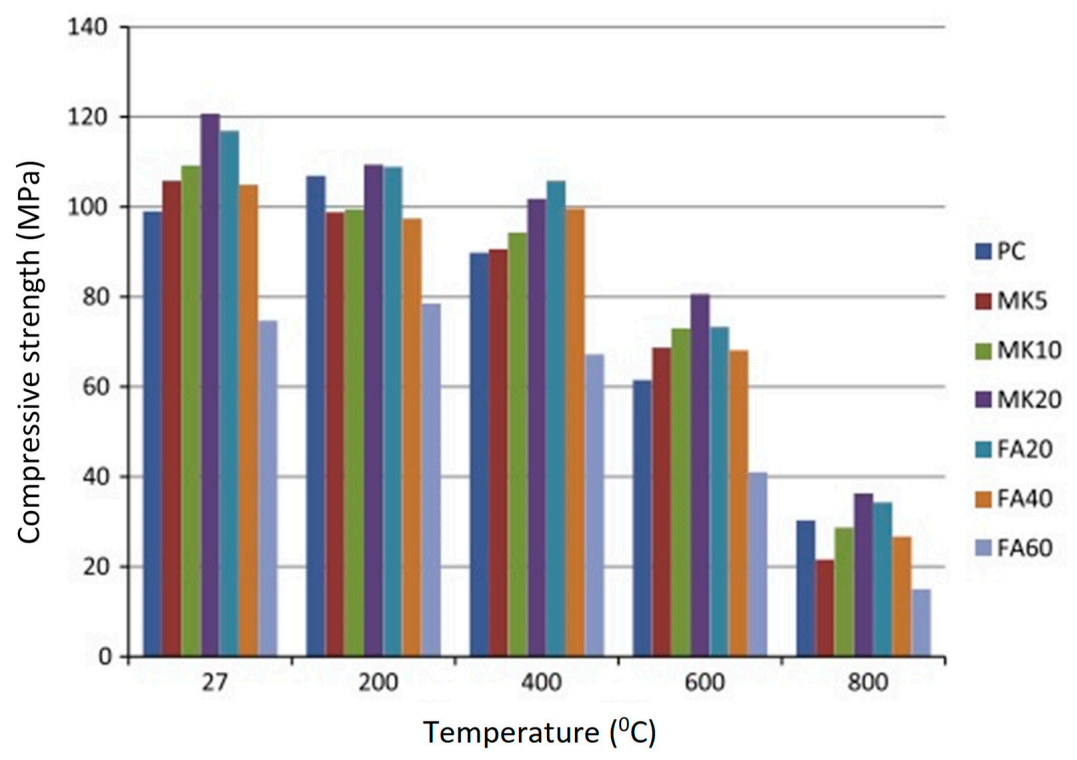

Figure 4. Effect of $\mathrm{FA}$ and $\mathrm{MK}$ on the mortar strength at different temperatures [67]. $[\mathrm{PC}=$ Portland cement $]$.

FA poses a higher risk of heavy metal leaching, compared to BA and GGBS. Some metals like Ti, $\mathrm{Mo}, \mathrm{B}$, and $\mathrm{Cu}$ had a higher degree of release from the stabilized cement-FA mixture. The presence of chloride and sulphate in FA may have caused this phenomenon [95]. In addition, metallic $\mathrm{Al}$ and $\mathrm{Zn}$ of FA may produce $\mathrm{H}_{2}$ during cement hydration. A significant amount of $\mathrm{H}_{2}$ might result in expansion and voids in cement-based materials [161].

\subsection{Bottom Ash (BA)}

\subsubsection{Effects on Flowability}

The effect of BA on the mortar flowability depends on its particle size and treatment process. Ground or sieved BA of $425 \mu \mathrm{m}$ size enhanced the flowability of mortar mixture; $21 \%$ of both ground and sieved BA provided a flow spread in the range of $225-232 \mathrm{~mm}$, while the OPC mortar had a flow spread of $158 \mathrm{~mm}$; the advantage of using sieved BA lies in retaining the flowability of mortar mixture for a longer time. The mortar with sieved BA lost a little amount of flow after $1 \mathrm{~h}$ following the completion of mixing compared to the mortar containing ground BA as well as the control mortar with $100 \%$ OPC; after $1 \mathrm{~h}$, the flow spread of the mortar including sieved BA was above $220 \mathrm{~mm}$; the mortar with ground BA and the control mortar had 199 and $130 \mathrm{~mm}$ flow spread, respectively; the presence of a higher level of washable carbon in ground BA may have caused this phenomenon [37]. Besides, the mortar with $41 \%$ pulverized BA of mean particle size $4.5 \mu \mathrm{m}$ yielded $14 \%$ higher flowability than the OPC mortar; the same amount of BA of size $6.3 \mu \mathrm{m}$ provided a flow spread of $112 \mathrm{~mm}$, which was a little higher than that given by $4.5 \mu \mathrm{m}$ BA [32]. Smaller BA particles are subjected to higher Brownian motion but require more water to cover their surface with the same film thickness. These two opposing conditions significantly influence the overall effect of BA on the flowability of mortar mixture.

\subsubsection{Effects on Strength}

The particle size, surface fineness, treatment process, and quantity of BA influence the strength of mortar. The particle size distribution of BA also influences the mortar strength. For 0-2 mm particles, $6 \%$ biomass BA provided the 28 days compressive strength of $52 \mathrm{MPa}$, which is $89.4 \%$ of the strength 
of the control mortar; for any further addition, the compressive strength decreased; high porosity, high organic matter content (5.26\%), and high abrasion susceptibility (29\%) were responsible for this drop in strength [97]. Crushing to a particle size finer than $125 \mu \mathrm{m}$, combusting at $800{ }^{\circ} \mathrm{C}$ for $18 \mathrm{~h}$ and removing lightweight particles by flotation were applied to improve the quality of biomass BA; among these techniques, crushing was the most effective; for a 13\% crushed biomass BA, the compressive strength was increased from $25 \mathrm{MPa}$ to $36 \mathrm{MPa}$; the application of all three processes on the same sample provided $52 \mathrm{MPa}$ strength for the mortar with the same BA content, while the OPC mortar strength was $58 \mathrm{MPa}$ [33]. The positive impact of BA was observed when it was ground to a size finer than OPC; the mortar with $10 \%$ such BA provided the 28 days compressive strength of $54 \mathrm{MPa}$, which was a little higher than that of the corresponding control mortar; in the case of $25 \%$ such BA, the mortar samples still passed the minimum strength requirement of $42.5 \mathrm{MPa}$ [34]. The pulverized sub-bituminous BA was milled for 0.5 and $3 \mathrm{~h}$ to make it two and three times finer than OPC (mean particle size of $6.3 \mu \mathrm{m}$ and $4.5 \mu \mathrm{m}$; Blaine fineness of $800 \mathrm{~m}^{2} / \mathrm{kg}$ and $1000 \mathrm{~m}^{2} / \mathrm{kg}$ ), respectively; for $9 \%$ cement replacement, the mortar with such BA gained $4.3 \%$ and 10.7\% higher strength than the control mortar [32]. After ball milling for $2 \mathrm{~h}$ and sieving by $300 \mu \mathrm{m}$ sieve, 5\% BA mortar provided $82 \mathrm{MPa}$ compressive strength at 28 days, compared to the $78 \mathrm{MPa}$ compressive strength of the control mortar; $20 \%$ BA mortar provided $85 \%$ strength of the control mortar at 28 days [35]. The compressive strength dropped for $10 \%-20 \%$ coal BA with the particle size finer than $425 \mu \mathrm{m}$ (ground or sieved); 67-72 MPa strength was reported at 28 days for the mortars with this replacement range, while the control mortar had a compressive strength of $79 \mathrm{MPa}$ [37]. Surprisingly, the mortar containing BA of particles finer than $300 \mu \mathrm{m}$ lost about $32 \%-42 \%$ of its 28 -day strength at 180 days; 454,000 parts per billion ( $\mathrm{ppb}$ ) of potassium $\left(\mathrm{K}^{+}\right)$ions were detected in the solutions (water plus dissolved salts) processed from the water absorption test of $30 \%$ BA mortar samples; this value was only 52,700 ppb for the control mortar samples; ASR may have occurred at this high concentration of dissolved $\mathrm{K}^{+}$ions, resulting in degradation of amorphous, as well as crystalline silica: the progressive dissolution of $\mathrm{K}^{+}$ions in ASR imparts the loss of mechanical properties at later ages [35].

\subsubsection{Effects on Durability and Other Properties}

The water sorption and porosity of mortar progressively increase with the biomass BA content $[33,97]$. Crushing biomass BA down to $125 \mu \mathrm{m}$ improves the situation, though the water sorption and porosity of BA mortar still remain higher than those of the control mortar; at 28 days, the porosity of the mortars with $0 \% \mathrm{BA}(100 \% \mathrm{OPC}), 13 \% \mathrm{BA}$, and 13\% crushed BA was recorded as $9.12 \%, 10.86 \%$, and $10.62 \%$, respectively; a similar trend was observed for water sorption. At the same age, the recorded sorption values were 3.4,5.12, and $5.04 \mathrm{~kg} / \mathrm{m}^{2} \cdot \mathrm{min}^{1 / 2}$, respectively [33]. Another study revealed that the water absorption and porosity of BA mortar increased during the longer curing period in contrast with the OPC mortar; the water absorption rate of $20 \% \mathrm{BA}$ mortar was $5.3 \%$ and $10.1 \%$ at 28 and 180 days, respectively [35]. The release of $\mathrm{K}^{+}$ions from BA may have triggered the disintegration of silica to cause ASR in mortar and therefore increased the water absorption at later age [35].

The presence of BA improves the resistance of mortar against sulphate attack and ASR; a past study showed that the positive effect of BA is more prominent at higher replacement levels $(25 \%-35 \%)$; on the other hand, the BA mortar mixtures were less resistant to carbonation and freezing-thawing action [146]. In addition, the change in the length of the mortar samples in shrinkage test increases with the content of BA, although it stays below the maximum permissible value of $0.05 \%$ up to $30 \%$ replacement $[33,35,162]$. The treatments with calcination and combustion along with the removal of light particles significantly reduce shrinkage [33]. After 32 days curing, the autogenous shrinkage of the mortar containing 10\%-20\% BA was lower than that of the control mortar [37]. Furthermore, the use of BA may cause leaching of various chemicals (e.g., Al, Sr, Na, K, Ca, Si, S, P) from the mortar mixture; at ambient temperature, a lower $\mathrm{pH}$ causes higher leaching [34]. Similar alkalinities of cement 
and incinerator BA and cement solidification mitigate the risk of leaching, making BA a favorable material for cement replacement [98].

\subsection{Silica Fume (SF)}

\subsubsection{Effects on Flowability}

Because of having much lower particle size and high surface area than OPC, SF reduces the flowability of the fresh mortar mixture at a given water content. Higher surface area requires more water to create the same water film thickness surrounding the particles. Turk [26] has reported inferior flow for the 5\%-20\% cement replacement with SF. The mortar mixture including $15 \%$ SF exhibited 7\% less flowability than the mortar mixture with $100 \%$ OPC [46]. The inclusion of SF causes a significant rise in flow time due to increased viscosity. The mortar mixture with $20 \% \mathrm{SF}$ resulted in $90 \mathrm{~s}$ flow time, compared to only $2 \mathrm{~s}$ flow time for the OPC mortar mixture. However, $\mathrm{CaSi}$ type SF $\left(73 \% \mathrm{SiO}_{2}\right.$ and $18 \%$ $\mathrm{CaO}, \mathrm{BET}$ fineness from $22 \mathrm{~m}^{2} / \mathrm{g}$ ) had no impact on the viscosity of the freshly mixed mortar, when the cement replacement was less than $10 \%$ [39].

Condensed SF (specific surface area, $13.3 \times 10^{6} \mathrm{~m}^{2} / \mathrm{m}^{3}$, as obtained using the method proposed by Hunger and Brouwers [163]) lowers the minimum w/b ratio required for the mortar mixture to flow and increases the flowability at the same $\mathrm{w} / \mathrm{b}$ ratio [135]. The incorporation of SF increases the paste volume for a given $\mathrm{w} / \mathrm{b}$ ratio because of its lower specific gravity than cement (refer to Table 2). Consequently, it can increase the mortar flowability through enhanced dispersion of aggregate particles. Furthermore, the higher Brownian motion of small SF particles causes a positive impact on the mortar flowability. At the $\mathrm{w} / \mathrm{b}$ ratio of $0.45,7.3 \%$ condensed SF induced a flow spread of $269 \mathrm{~mm}(369 \mathrm{~mm}$, without subtracting the base diameter) and a flow rate of $535 \mathrm{ml} / \mathrm{s}$, while it was only $210 \mathrm{~mm}(310 \mathrm{~mm}$, including the base diameter of the cone) and $405 \mathrm{ml} / \mathrm{s}$, respectively, in the case of the control mortar [135,164]. Because of the size gap between cement and condensed SF particles, it is recommended to add another SCM of intermediate size for a better flowability [165]. The use of FA microsphere (specific surface area: $3.95 \times 10^{6} \mathrm{~m}^{2} / \mathrm{m}^{3}$ found by the Hunger and Brouwers method [163]) combined with condensed SF showed a good synergistic effect [135].

\subsubsection{Effects on Strength}

SF consumes the $\mathrm{Ca}(\mathrm{OH})_{2}$ crystals released from the cement hydration process, leading to the formation of secondary $\mathrm{C}-\mathrm{S}-\mathrm{H}$. This $\mathrm{C}-\mathrm{S}-\mathrm{H}$ reduces porosity, improves the interfacial bond between aggregate particles, and thus increases the strength properties of mortar. At the ages of 28 and 90 days, $10 \%$ SF produced the greatest mortar strength among $5 \%-20 \%$ cement replacements $[26,39,46]$; the mortar with $10 \%$ SF gained the compressive strength of $81 \mathrm{MPa}$ at 90 days [39]. Having a larger specific surface area or surface fineness than cement, SF can reduce segregation and bleeding tendency even at higher SP dosages [101,166], thus contributing to higher strength. In one study, the mortar with 15\% SF required 3.28\% SP (by weight of binder) and gained 63.8 MPa strength at 28 days compared to the 54.4 MPa compressive strength of the control mortar without any SF where only $1.56 \%$ SP was used; the use of more SP allowed lower w/b ratio and improved compaction [136]. At later ages, higher SF contents may perform slightly better. The mortar with $20 \% \mathrm{SF}$ achieved $65.2 \mathrm{MPa}$ compressive strength at 91 days, whereas the mortars including $10 \% \mathrm{SF}$ and $0 \% \mathrm{SF}(100 \% \mathrm{OPC})$ provided $62.6 \mathrm{MPa}$ and 60.6 MPa strength, respectively, at the same age [26]. However, an increase in CaSi SF content from 5\% to $20 \%$ led to a linear decrease in compressive strength; $20 \%$ CaSi SF caused a $35 \%$ decrease in 28 -day strength [39].

Condensed SF has a high specific surface area of $13.3 \times 10^{6} \mathrm{~m}^{2} / \mathrm{m}^{3}$ (measured by the Hunger and Brouwers method [163]) because of extremely low particle size. Thus, the inclusion of condensed SF decreases the optimum $\mathrm{w} / \mathrm{c}$ ratio and increases the mortar strength. The mortar with $7.3 \%$ condensed SF had an optimum w/c ratio of 0.199 and achieved 117.6 MPa compressive strength at 28 days but it was 0.289 and $96.2 \mathrm{MPa}$ strength was obtained in the case of the control mortar [135]. Not only the 
particle size and surface area but also the size distribution of SF particles affects the strength properties of mortar. The mortar including SF with an average particle size of $12 \mu \mathrm{m}$ and a size distribution over 0-150 $\mu \mathrm{m}$ showed lower strength than the control mortar with 100\% OPC. On the contrary, the mortar including $25 \% \mathrm{SF}$, with a $45-\mu \mathrm{m}$ sieve residue of $0.98 \%$ and a size distribution over $0-600 \mu \mathrm{m}$, provided $3.5 \%$ more strength at 28 days; therefore, a $0.98 \%-4.13 \%$ residue on the $45-\mu \mathrm{m}$ sieve is advisable for the use of SF in high performance mortar [137]. In the presence of 5\%-35\% LP, SF replacement causes an adverse effect on the strength of mortar due to the reduction of hydraulically active clinker fraction of cement [46].

\subsubsection{Effects on Durability and Other Properties}

As the proportion of SF goes up, the density of mortar goes down due to the lower unit weight of SF compared to that of cement [26]. However, smaller condensed SF particles cause a rise in packing density and a drop in void ratio; a $7.3 \%$ cement replacement caused $8.84 \%$ rise in packing density and $30.75 \%$ drop in void ratio [135]. In the mortar containing SF, ettringite is only formed inside the pores; the expansion values of SF mortar are lower than those of OPC mortar upon 300 days sulphate exposure due to the absence of needle-like ettringite on the outside of the pores [43]. The mortar samples with $8 \%$ cement replacement by SF experienced an expansion of less than $0.1 \%$ after 12 months immersion in sulphate solution at $23^{\circ} \mathrm{C}$; the improvement in sulphate resistance was more evident at $5{ }^{\circ} \mathrm{C}$ [148]. A combination of $10 \% \mathrm{SF}$ and $90 \%$ OPC conforms with the requirements of sulphate resisting cement [152,167]. The chloride resistance of mortar also increases when SF is used. Only $10 \%$ SF can lessen the chloride charges passed by 75\% and keep them below 1000 coulombs [43], which is categorized as "very low" in accordance with ASTM C1202 $[43,168]$. In the presence of micro-SF and/or nano-SF, the carbonation depth of mortar also decreases significantly. The inclusion of $10 \%$ micro-SF (finer than $0.5 \mu \mathrm{m}$ ) can cut the carbonation depth of the control mortar by $25 \%$ after 28 days of carbonation. Similar improvement was achieved by $1 \%$ nano-SF (5-20 nm size) [150]. The mortar samples including $5 \%-10 \%$ SF experienced a mass loss of less than $4 \%$ after immersion in sulphuric acid ( $\mathrm{pH}=1)$ for 390 days. This value was better than that of the control mortar samples, which had $9 \%$ mass loss on average. In the case of acetic acid $(\mathrm{pH}=3), 390$ days sulphate exposure caused about $50 \%$ mass loss for the mortar samples containing $0 \%-10 \%$ SF [151]. The formation of secondary C-S-H also improves the resistance against ASR; $10 \%$ replacement of OPC by SF decreased the expansion of mortar samples from $0.19 \%$ to $0.02 \%$ after 14 days of exposure to $\mathrm{NaOH}$. This value was much lower than the allowable maximum limit of $0.10 \%[152,169]$. The water absorption of mortar is also decreased in the presence of SF. The incorporation of $10 \%$ SF dropped the water absorption value to $1.8 \%$, which was $60 \%$ less than the absorption value of the control mortar [43]. This value is specified as "good" in accordance with CEB-FIP $[43,170]$. The effect of SF on the thermal conductivity of mortar is also negligible [47]. Moreover, SF shows superior performance against frost-action in the absence of air-entraining agents. The loss in mass and compressive strength of the control mortar was $1.36 \%$ and $26 \%$, respectively, after 300 freeze-thaw cycles; with $10 \% \mathrm{SF}$, these values fell off to $0.48 \%$ and $7 \%$, respectively [43]. The properties like carbonation and sulphate resistances are mostly influenced by the pozzolanic activity of SF. A small amount (1\%-2\%) of nano-SF can achieve the equivalent resistance of a much higher amount $(10 \%-20 \%)$ of micro-SF. On the contrary, the properties like porosity, water absorption, and chloride penetration depend on both the pozzolanic and filler effects of SF. Only SF nanoparticles may not provide a satisfactory level of performance in such cases. A combination of micro-SF and nano-SF is recommended to achieve good durability of mortar [150].

\subsection{Ground Granulated Blast-Furnace Slag (GGBS)}

\subsubsection{Effects on Flowability}

GGBS enhances the flowability of mortar mixture due to its conducive surface characteristics. With the addition of GGBS, the flowability can be enhanced for $10 \%-30 \%$ cement replacement. At 
$30 \%$ substitution, the flow spread of mortar was raised by $28 \mathrm{~mm}$ (from $204 \mathrm{~mm}$ to $232 \mathrm{~mm}$ ) [49]. The influence of GGBS on the mortar flowability depends largely on the surface morphology of GGBS particles. GGBS consisting of particles with smoother surface enhances the flowability of mortar mixture [153].

\subsubsection{Effects on Strength}

Although 10\% GGBS resulted in lower compressive strength, larger amounts showed a significant improvement in the mortar strength as compared with OPC alone [49]. For 50\% GGBS, the compressive strength of mortar was increased by $4.6 \%-15.1 \%$ depending on the binder content and SP dosage [50]. The positive effect of GGBS on the mortar strength is more pronounced at a lower binder content. The highest compressive strength $(56.7 \mathrm{MPa})$ was achieved at $1: 2$ binder-to-sand ratio and $0.4 \% \mathrm{SP}$. The mortar with 60\% cement replacement had a similar strength as compared with the control mortar [50]. In another investigation, 30\% GGBS showed a better strength than 50\% GGBS [60]. At high-temperature curing, the loss in strength is higher in the mortars with GGBS; however, both 30\% and 50\% GGBS can retain a better strength at least up to $60^{\circ} \mathrm{C}$ curing temperature [60].

The strength development is slower in GGBS mortars. The half-strength age of the mortar with $50 \%$ GGBS is 13.4 days whereas it is only 3.4 days for the mortar with no GGBS. This gap closes with the rise in curing temperature. At $60^{\circ} \mathrm{C}$, the half-strength age of the above-mentioned mortars is 1.2 days and 1 day, respectively [60]. In binary blending with calcium aluminate cement (CAC), GGBS converts $\mathrm{CAH}_{10}$ (monocalcium aluminate decahydrate) mostly to $\mathrm{C}_{2} \mathrm{ASH}_{8}$ (straetlingite) instead of $\mathrm{C}_{3} \mathrm{AH}_{6}$ (katoite) up to 210 days; it hinders the strength reduction due to the conversion of $\mathrm{CAH}_{10}$ to $\mathrm{C}_{3} \mathrm{AH}_{6}$; thus, the strength progressively increases beyond 28 days [48]. This eliminates the primary drawback of using pure CAC under hot climatic conditions. With the inclusion of $80 \%$ GGBS, 20\% loss in ultimate strength turns into $50 \%$ gain at $20^{\circ} \mathrm{C}$; a GGBS content of more than $40 \%$ causes the formation of stable straetlingite $\left(\mathrm{C}_{2} \mathrm{ASH}_{8}\right)$, hindering the formation of $\mathrm{C}_{3} \mathrm{AH}_{6}$, resulting in less porosity and more strength; the mortar with $40 \%$ GGBS achieves an ultimate compressive strength more than $40 \mathrm{MPa}$ if cured continuously at $50{ }^{\circ} \mathrm{C}$ for 210 days; the same mortar reached $75.7 \mathrm{MPa}$ when cured at $20{ }^{\circ} \mathrm{C}$ for 28 days and then at $50{ }^{\circ} \mathrm{C}$ for 182 days [48].

\subsubsection{Effects on Durability and Other Properties}

The slow rate of pozzolanic reaction causes high porosity and water absorption for GGBS mortar at an early age. After 28 days, both 20\% and 30\% GGBS show a better performance. The mortar with 30\% GGBS had a water absorption value less than 12\% [49]. In addition, GGBS improves the resistance of mortar against sulphate attack. Pozzolanic reaction leaves very little $\mathrm{Ca}(\mathrm{OH})_{2}$ to form ettringite and reduces the permeability of mortar by closing pore openings with secondary $\mathrm{C}-\mathrm{S}-\mathrm{H}$. Additionally, GGBS does not contribute to increase the quantity of $\mathrm{C}_{3} \mathrm{~A}$ in mortar. These effects help to resist sulphate attack [153]. The mortar samples with only 20\% GGBS expanded less than $0.10 \%$ after 12 months immersion in a sulphate solution. At $5{ }^{\circ} \mathrm{C}, 60 \%$ GGBS kept the mortar samples intact ( $<0.1 \%$ expansion) even after 45 months immersion in $\mathrm{Na}_{2} \mathrm{SO}_{4}$ solution [148]. The chloride diffusion rate drops with the inclusion of GGBS up to 50\% replacement of OPC. The mortar samples without GGBS had observable chloride ions after 45 days, while $30 \%$ GGBS had a breakthrough time of 73 days with $60 \%$ smaller diffusion coefficient. After 270 days, the chloride concentration in the mortar samples with $0 \%, 30 \%$ and 50\% GGBS was 1000, 370, and $40 \mathrm{mg} / \mathrm{l}$, respectively [154]. With an increase in GGBS content, the electrical resistivity of mortar increases for SSD (saturated surface-dry) condition and decreases for OD (oven-dry) condition. The mortar with 20\% GGBS showed very close values in both conditions as compared with the control mortar [49]. 


\subsection{Limestone Powder (LP)}

\subsubsection{Effects on Flowability}

The grindability of limestone is higher than that of cement clinker. Hence, LP has a wider particle size distribution compared to cement. Fine granulated limestone particles can fill in the wide size-range pores between cement particles and lessen water requirement [46]. For this reason, the mortar flowability rises with the increased quantity of LP [25,46]. In the study of İnan Sezer [46], the mortar including 35\% LP gave a flow spread of $147 \mathrm{~mm}$. A similar trend was observed in the presence of pozzolanic materials (e.g., SF, FA). For 15\% LP, a flow spread greater than $136 \mathrm{~mm}$ was recorded in the presence of SF and FA [25]. The use of 30\%-70\% LP led to a slightly greater reduction in the requirements of both water and SP than FA to ensure self-compatibility [56]. For self-compacting mortar, the optimum LP content for good flowability is $10 \%-15 \%$. A flow spread of higher than $300 \mathrm{~mm}$ and a V-funnel flow time of less than $4 \mathrm{~s}$ were achieved in this LP range [138]. The viscosity becomes consistently higher in a mortar with LP. The highest viscosity was attained at 30\% LP [138]. The higher fineness of LP may also enhance the spreading of mortar mixture due to the greater Brownian motion of smaller particles. The use of $10 \%$ LP, passing mesh \#1500, induced a flow spread greater than $135 \mathrm{~mm}$ at the $\mathrm{w} / \mathrm{c}$ ratio of 0.35 [25]. The cement paste volume (the volume of water plus the solid volume of cement in a mortar) has a significant impact on the effectiveness of LP in enhancing the mortar flowability. At a higher cement paste volume, the use of LP is more effective to increase the flow spread of mortar; the positive impact of LP on the flowability of mortar mixture was only observed if the cement paste volume was at least $58 \%$ [139].

\subsubsection{Effects on Strength}

The chemical reaction of LP with the alumina phases of cement produces carbo-aluminates, which fill in pore spaces in mortar. Thus, the incorporation of LP contributes to the strength of mortar by filler effect. After the consumption of all the available alumina, the excess LP cannot react to add to the strength of cement-based materials [140]. The optimum level of LP was suggested as $2.4 \%$ with respect to the maximum compressive strength of non-self-compacting mortar; for this optimum LP content, about $20 \%$ more compressive strength was achieved at 28 days [140]. For self-compacting mortar, the optimum LP content for good strength lies in the range of $16 \%-23 \%$, which provided $50 \mathrm{MPa}$ compressive strength at 28 days $[55,138]$. An excessive amount of LP is not conducive to the compressive strength of mortar. The use of 50\% LP resulted in a 33\% drop in 28-day strength, although it had a better early (2 days) strength [59]. Some other studies had contradictory findings about the effect of LP on the strength of mortar. For 5\%-35\% LP, a drop in compressive strength was observed at all ages [41,46]. The incorporation of 35\% LP provided only 59\% compressive strength of the control mortar at 28 days [46]. The effect of LP on strength is highly influenced by the cement paste volume of mortar mixture. The strength is impacted positively by LP only for the cement paste volume of $50 \%$ or larger; the mortar with $50 \%$ cement paste volume reached the highest level of strength; the use of $36 \%$ LP provided $60 \mathrm{MPa}$ compressive strength at 28 days that was $6.8 \%$ higher than the strength of the control mortar [139].

\subsubsection{Effects on Durability and Other Properties}

As a filler, LP lowers the water requirement of mortar mixture for a given flowability, and thus decreases its porosity; on the other hand, the reduction in cement content increases the effective w/c ratio, which causes more porosity [171]. The interaction between these two effects determines the end effect of LP, which is highly influenced by the amount and fineness of LP [107]. Practically, the effect of $20 \%-30 \%$ LP on the porosity of cement paste is insignificant; the porosity increases linearly with further addition. Several recent studies reported a higher porosity after the inclusion of LP, whereas many studies reported the opposite trend; few published works showed a lower porosity up to an optimum level of $15 \%-18 \%$-more LP above this range resulted in a higher porosity [107]. In combination 
with the other SCMs (e.g., FA, GGBS, SF, MK), LP improves the pore structure related properties (e.g., porosity, absorption, permeability) if used with an appropriate amount [107]. The packing density decreases as the LP content increases at a fixed cement paste volume. The packing density dropped from 0.720 to 0.705 for a rise in LP content from $0 \%$ to $34 \%$ at $50 \%$ cement paste volume [139]. Usually, the sulphate resistance of mortar is not affected by LP content. However, higher cement replacement levels with LP may cause earlier failure due to sulphate attack [148,149]. Torres et al. [155] have expressed their concern for exposure to low-temperature and marine environments. They observed that the mortar samples with 5\%-35\% LP underwent higher deterioration than the control mortar samples with $100 \%$ OPC when stored in $1.8 \% \mathrm{MgSO}_{4}$ solution for 5 years. The extent of deterioration increases with the content of LP. The mortar samples with 5\% LP took 5 years to have higher deterioration than the samples with 15\% LP had after 1 year [155]. Moreover, together with white Portland cement, 31.9\% LP caused a hike in carbonation depth; after 7 days of exposure to $1 \%(\mathrm{v} / \mathrm{v}) \mathrm{CO}_{2}$ at $20{ }^{\circ} \mathrm{C}$ and $57 \%$ relative humidity, there was a measurable degree of carbonation; the carbonation rate was $0.85 \mathrm{~mm} / \mathrm{d}^{1 / 2}$ while it was only $0.17 \mathrm{~mm} / \mathrm{d}^{1 / 2}$ for the samples without LP, up to 280 days of exposure [58].

\subsection{Metakaolin (MK)}

\subsubsection{Effects on Flowability}

A significant increase in viscosity and a decrease in flowability are associated with the incorporation of MK [65]. The mean diameter $\left(D_{50}\right)$ of MK particles is approximately three times smaller than that of cement. The higher specific surface area or surface fineness and smaller particle size of MK have an adverse effect on the flowability of mortar mixture [64]. The calcination method has a second-order influence on the shape of particles; the smaller particles can have smoother surface through the flash calcination process [65]. In mortar, $42 \%$ reduction in fluidity was observed with $25 \%$ MK [64]. In addition, MK incorporation reduces segregation in mortar. In a recent study, 15\% MK enabled to raise the $\mathrm{w} / \mathrm{c}$ ratio from 0.35 to 0.41 at a segregation index of $20 \%$ [64].

\subsubsection{Effects on Strength}

The partial replacement of cement with MK improves the strength properties of mortar, showing more prominent influence at a lower w/c ratio [64]. The mortar prepared with a w/b ratio of 0.17 and $10 \%$ MK achieved the highest compressive strength; the compressive strength of the plain mortar (unreinforced mortar) with $10 \% \mathrm{MK}$ was above $80 \mathrm{MPa}$ at 28 days. In the presence of MK, the flexural strength followed the same trend for the reinforced mortar but dropped for the unreinforced mortar. MK promotes homogeneous dispersion and enhances the bonding of steel fibers in cementitious matrix, thus improving the flexural strength of reinforced mortar [66]. The flexural and impact strengths rise with the MK content up to $15 \%$; however, $10 \%$ MK maximizes the enhancement, which is about $34 \%$ [141,142]. In another study, the mortar made with a w/b ratio of 0.30 and $20 \% \mathrm{MK}$ gained $120 \mathrm{MPa}$ compressive strength at 28 days, which was $21 \%$ higher than the strength of the control mortar [67]. Furthermore, the mortar produced with a w/b ratio of 0.485 and $10 \%$ MK provided the same strength as the control mortar at 28 days and $10 \%$ more strength at 300 days [43].

When used together, $\mathrm{MK}$ virtually eliminates the chemical retardation effect of $\mathrm{ZnO}$, which enables the waste materials containing $\mathrm{ZnO}$ (e.g., electric arc furnace dust) to be used in cement-based materials. The MK-ZnO combination containing $1 \% \mathrm{ZnO}$ calcined at $650{ }^{\circ} \mathrm{C}$ had $23 \%$ improvement in compressive strength. The strength increased with the calcining temperature in the range of $500-650{ }^{\circ} \mathrm{C}$; at the calcined temperatures of $600{ }^{\circ} \mathrm{C}$ and $650^{\circ} \mathrm{C}$, both the mortars with and without $\mathrm{ZnO}$ achieved a higher strength than the OPC mortar [144].

MK nanoparticles (Blaine fineness of $48 \mathrm{~m}^{2} / \mathrm{g}$ and average dimensions of $100 \times 50 \times 10 \mathrm{~nm}$ ) have both the filler and pozzolanic effects, which enhance the strength of mortar. On the other hand, at higher contents, they reduce the $\mathrm{C}_{3} \mathrm{~S}$ and $\beta-\mathrm{C}_{2} \mathrm{~S}$ phases in blended cement and agglomerate around the OPC grains, hindering the hydration of cement. As a result of these opposing effects, the compressive 
strength increases with the increasing replacement of cement up to $5 \%$, then it decreases with any additional amount of nano-MK; 23\% higher compressive strength was attained for 5\% nano-MK [145].

\subsubsection{Effects on Durability and Other Properties}

The incorporation of MK forms a larger fraction of the pores that are connected to the external surface through smaller neck entrances; thus, a drop in resistance against carbonation occurs in the mortar which contains MK [58]. The mortar with 31.9\% MK in a dual combination with white Portland cement suffered a measurable level of carbonation at 7 days for exposure to $1 \%(\mathrm{v} / \mathrm{v}) \mathrm{CO}_{2}$ at $20{ }^{\circ} \mathrm{C}$ and $57 \%$ relative humidity. After 280 days, the carbonation coefficient was $0.61 \mathrm{~mm} / \mathrm{d}^{1 / 2}$, while it was only $0.17 \mathrm{~mm} / \mathrm{d}^{1 / 2}$ for the mortar sample without MK [58]. The use of $10 \% \mathrm{MK}$ reduced the water absorption value from $4.2 \%$ to $<3 \%$, which is the maximum limit specified for "good" quality of cement-based materials according to CEB-FIP $[43,170]$. MK raises the resistance of mortar against sulphate attack; in the mortar containing MK, ettringite is only formed inside instead of both inside and outside of the pores [43]. The mortar with only 10\% MK can survive the sulphate exposure beyond 300 days $[43,148]$. The mortar samples with 10\%-20\% MK suffered an expansion rate which was only half of that of the control mortar samples after exposure to 50 and $150 \mathrm{~g} / \mathrm{l} \mathrm{Na}_{2} \mathrm{SO}_{4}$ solution for 180 days. Even in $150 \mathrm{~g} / \mathrm{l}$ solution, the mortar samples containing $15 \%-20 \%$ MK had less than $0.1 \%$ expansion after 180 days [156]. The mortar samples incorporating 18\% MK and 4\%-10\% LP sustained 540 days of exposure in sulphate solution at $5{ }^{\circ} \mathrm{C}$ [148]. At normal temperature, $\mathrm{MK}$ increases the chloride ion penetration resistance of mortar; $10 \% \mathrm{MK}$ caused $65 \%$ reduction in the charge passed; the chloride ion penetration values of the mortar samples containing 10\% MK were 1000-2000 coulombs, specified as "low chloride ion penetrability" in accordance with ASTM C1202 [43,168]. Mlinarik and Kopecskó [151] also have reported similar improvement. However, MK affects adversely the chloride ion penetration resistance if the temperature is above $400^{\circ} \mathrm{C}$ because the denser hydration product of MK mortar suffers more due to internal cracking caused by evaporable water; at $600{ }^{\circ} \mathrm{C}, 20 \% \mathrm{MK}$ turned "moderate" chloride ion penetrability into "high" $[67,168]$. The partial replacement of cement by $\mathrm{MK}$ results in a drop of alkali that comes from the cement content of mortar mixture and thus reduces the possibility of ASR [156]. In addition, by pozzolanic reaction, MK lowers the permeability of the matrix and causes a drop in the $\mathrm{pH}$ of pore solution. For these reasons, MK improves the ASR resistance of mortar. The MK content of 15\%-20\% kept the mortar expansion below $0.1 \%$, which is considered the maximum safe limit [156]. Although the application of MK was found very effective in the case of sulphuric acid attack, it could not perform well against acetic acid. The mortar with $10 \% \mathrm{MK}$ had a drop in mass loss from $9 \%$ to below $1 \%$ after 390 days of exposure to the sulphuric acid of $\mathrm{pH}$ value 1 . When it was exposed to the acetic acid of $\mathrm{pH}$ value 3 for 390 days, the loss in mass was almost 50\% for 0\%-17\% MK [151]. In addition, 10\% MK improves the resistance of mortar against freezing and thawing. After 300 cycles, the loss in compressive strength and mass was $11 \%$ and $0.7 \%$, respectively, for the mortar with $10 \% \mathrm{MK}$, while these losses were $26 \%$ and $1.36 \%$ for the OPC mortar [43]. The shrinkage reduction at later ages (56 days) was also remarkably improved due to the partial cement replacement by MK [64].

The mortar samples containing MK continuously lose compressive strength with increased temperature; at $200{ }^{\circ} \mathrm{C}, 400{ }^{\circ} \mathrm{C}, 600{ }^{\circ} \mathrm{C}$ and $800{ }^{\circ} \mathrm{C}$, as much as $9 \%, 15 \%, 35 \%$, and $79 \%$ strength loss occurred, respectively; the mortar with $20 \% \mathrm{MK}$ had more strength than the control mortar after exposure to the higher temperature up to $800{ }^{\circ} \mathrm{C}$; the MK mortar samples retained $80 \%$ of the unheated strength only up to $400{ }^{\circ} \mathrm{C}$; therefore, MK mortar should be used carefully for the structures with a risk of being exposed to a temperature of $400{ }^{\circ} \mathrm{C}$ and above, [67]. The nanoparticles of $\mathrm{MK}$ affect the strength of mortar differently. At high temperatures (up to $800{ }^{\circ} \mathrm{C}$ ), the higher $(5 \%-15 \%)$ the nano-MK content, the better is the strength. The exposure to $250{ }^{\circ} \mathrm{C}$ and $800{ }^{\circ} \mathrm{C}$ for $2 \mathrm{~h}$ resulted in a rise of $36.6 \%$ and a drop of $46.5 \%$ strength, respectively, for the mortar with $15 \%$ nano-MK, while the respective values were $28.4 \%$ and $57 \%$ for the OPC mortar [145]. 


\subsection{Volcanic Ash (VA)}

\subsubsection{Effects on Flowability}

The effects of cement replacement by VA on the flowability of mortar mixture have not been discussed in any of the recently published works. Existing literature on the fresh properties of the mortar with VA only discussed the setting time of mortar. Replacing cement with VA has a retarding effect on the initial and final setting times of mortar at normal temperature $\left(23 \pm 3^{\circ} \mathrm{C}\right)$ but an accelerating effect at a higher temperature $[60,68,71]$. Accelerated initial setting time is expected to cause a significant loss of the flowability of mortar mixture.

\subsubsection{Effects on Strength}

In most of the studies, the mortar strength decreased with an increase in its VA content; the 28-day compressive strength dropped by $17 \%-32 \%$ for $20 \%-25 \%$ VA, with a particle size in the range of 20.0-21.7 $\mu \mathrm{m}$ [68-71]. After 90 days curing, the mortar with 20\% VA achieved higher strength than the control mortar; the compressive strength of 40-42 MPa was reported for the mortar with VA compared to the control mortar strength of 34-40 MPa [60,69]. Finer particles and higher curing temperature showed significant improvements in the performance of VA mortar. The mortar samples with $20 \%$ VA of $320 \mathrm{~m}^{2} / \mathrm{kg}$ Blaine fineness achieved 10\% higher compressive strength than the control mortar samples $\left(100 \%\right.$ OPC) at 28 days, when the curing temperature was $20^{\circ} \mathrm{C}$. This effect was further enhanced with increased curing time and temperature. After 90 days curing at $60^{\circ} \mathrm{C}$, the mortars with 10\%-30\% VA obtained 33.1-33.4 MPa, compared to the 28.8 MPa compressive strength of OPC mortar [60]. For a rise in VA content up to $40 \%$, the total heat of hydration falls from $50.6 \mathrm{~kJ} / \mathrm{kg}$ to $35.0 \mathrm{~kJ} / \mathrm{kg}$, which makes the use of VA more desirable where thermal cracking is a major concern [68].

\subsubsection{Effects on Durability and Other Properties}

With the increased content of VA, the total pore volume and electrical resistivity of mortar rise and its chloride ingress falls; for $40 \% \mathrm{VA}$, the chloride concentration is 0 beyond $25 \mathrm{~mm}$ depth after 7 days curing, which is $45 \mathrm{~mm}$ for the control mortar; after 120 days curing, the chloride diffusion coefficient is higher in the mortar without any VA than in the mortars containing $20 \%-40 \% \mathrm{VA}$; in corrosion resistance test, the mortar samples with 20\%-40\% VA remained passive for 6 to 7 weeks compared to only 2 weeks for the mortar samples without VA; in corrosive environment, the mortar samples with $40 \%$ VA had only $0.12 \%$ mass loss and $5.1 \%$ corroded area after 365 days curing, while the respective values were $0.61 \%$ and $9.1 \%$ for the control mortar samples [70]. In addition, $25 \%$ VA kept the expansion due to ASR close to $0.05 \%$ after 14 days; this expansion was above $0.40 \%$ for the control mortar [69].

\subsection{Palm Oil Fuel Ash (POFA)}

\subsubsection{Effects on Flowability}

The use of unground POFA decreases the flowability of mortar mixture; $30 \%$ unground POFA needed more than double SP dosage to get a flowability which is close to that of the control mixture [111]. The grinding of POFA can compensate for its negative impact on the mortar flowability. The overall porosity of POFA particles becomes lower if they are ground to smaller sizes [77]. This means the absorption of water by POFA particles will be lower during the mixing process of mortar and thus more water will be available for its better flow. Also, smaller POFA particles will experience greater Brownian motion [120] and therefore they will enhance the mortar flowability. It was observed in an earlier study that the mortar with ground POFA can reach a very close flowability of the control mixture without any extra SP dosage [76]. The incorporation of equal amounts of POFA and pulverized burnt clay in a mortar mixture increases the saturation dosage of water-reducing admixture. In this case, the advantage of using POFA becomes more pronounced at higher $\mathrm{w} / \mathrm{b}$ ratios. The mortar mixture with 
$10 \%$ POFA and pulverized burnt clay ( $5 \%$ each) together had the best performance for the $\mathrm{w} / \mathrm{b}$ ratios of $0.30-0.40$; the highest flow spread $(310 \mathrm{~mm})$ was achieved for $10 \%$ cement replacement at $0.35 \mathrm{w} / \mathrm{b}$ ratio with $2 \%-2.25 \%$ water-reducing admixture [72].

\subsubsection{Effects on Strength}

POFA contributes to increase the strength in two ways, as a filler and through the pozzolanic effect. Again, the dilution effect counteracts the former effect. The ultimate effect of POFA on strength highly depends on its particle size, replacement level, and treatment process. Usually, the smaller particles produce higher strength because of greater reactivity and better micro-filling capability [77]. POFA of $82 \mu \mathrm{m}$ median particle size and $25.5 \mathrm{~m}^{2} / \mathrm{g}$ BET fineness had an adverse effect on the compressive strength of mortar at all ages and the strength decreased with the higher replacement level; the use of $20 \%$ POFA decreased the 28-day compressive strength by $22 \%$ [111]. The mortar incorporating POFA of $32 \mu \mathrm{m}$ median particle size and $0.357 \mathrm{~m}^{2} / \mathrm{g}$ BET fineness reached the compressive strength of the control mortar (100\% OPC) at 28 days for $10 \%$ replacement; any further increase in POFA content resulted in a lower strength [76]. The positive influence of POFA was found for the particle size of $12.3 \mu \mathrm{m}$ and Blaine fineness of $12,285 \mathrm{~cm}^{2} / \mathrm{g}$. For the mortars containing such POFA, the relative compressive strength was $100.5 \%-105.5 \%$ of the strength of OPC mortar at all ages for $10 \%-30 \%$ contents. Even the mortar including $40 \%$ such POFA provided 3.8\% more strength than the control mortar at 90 days [77]. The heat treatment followed by grinding significantly improves the strength performance of POFA [74]. Heating POFA at $500^{\circ} \mathrm{C}$ for $1 \mathrm{~h}$ and grinding until it reaches the median size less than $1 \mu \mathrm{m}$ resulted in $146 \%$ more fineness than OPC. After this treatment, ultrafine POFA reached the strength activity index of $105 \%$ at 28 days [74]. The heat treated POFA (ultrafine POFA) significantly improves the compressive strength of mortar, even at a very high replacement level of cement. The mortar containing $80 \%$ ultrafine POFA gained more strength than the control mortar with $100 \%$ OPC at all ages, as evident from Figure 5; at 28 days, it reached a compressive strength above $45 \mathrm{MPa}$ for $0.40 \mathrm{w} / \mathrm{b}$ ratio, which is far more than the strength of the control mortar [74]. In contrast, ground POFA obtained after drying at $105^{\circ} \mathrm{C}$ for $24 \mathrm{~h}$ and then grinding to $90 \%$ passing through $45-\mu \mathrm{m}$ sieve is not effective like ultrafine POFA in improving the compressive strength of mortar, particularly at a very high replacement level of cement, as can be seen from Figure 5; the mortar with $80 \%$ ground POFA provided lower compressive strength than the control mortar with 100\% OPC.

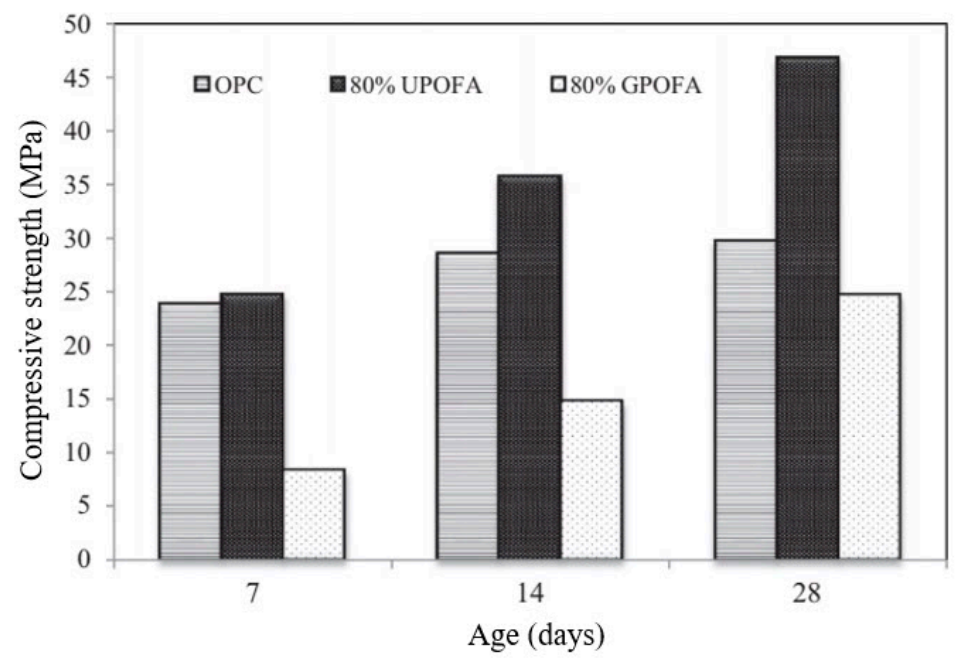

Figure 5. Effect of $80 \%$ POFA (before and after treatment) on the strength development of mortar [74]. [GPOFA = Ground POFA; UPOFA = Ultrafine POFA]. 


\subsubsection{Effects on Durability and Other Properties}

The incorporation of POFA may lead to a rise in the water absorption and permeable porosity of mortar at all ages depending on the particle size distribution of binder. Both water absorption and permeable porosity increased by more than $50 \%$ at 90 days for $30 \%$ POFA [111]. The use of $10 \%$ POFA gave a similar permeability as compared with the OPC mortar but higher replacements affected permeability adversely; $30 \%$ POFA increased the permeability of mortar by up to $200 \%$ at 28 days [76]. Furthermore, POFA mortar showed a better resistance against sulphate attack; the expansion values due to external sulphate attack were $0.046 \%-0.068 \%$ for the POFA mortars whereas the control mortar had an expansion value of $0.075 \%$; the expansion of mortar samples was reduced by $37 \%$ for $20 \%$ POFA [157].

The porous texture of POFA can entrap the free water (not considered as adsorbed water, which causes the disjoining pressure in capillaries); the removal of this moisture from the cement-based materials containing POFA does not cause shrinkage; besides, the low rate of pozzolanic reaction decreases the tensile strength that exerts on the walls of capillary pores. For these reasons, 30\% POFA caused $15 \%$ less drying shrinkage in the mortar samples at 28 days [76]. Moreover, the total heat of hydration decreases with an increased amount of POFA [75]. The high volume of POFA can be used in mortar for the circumstances where the prevention of volume change and thermal cracking due to extreme thermal stress is required $[74,75]$.

\subsection{Rice Husk Ash (RHA)}

\subsubsection{Effects on Flowability}

The porous nature, lower particle size, and higher surface fineness of RHA tend to increase the water requirement of mortar mixture for its flowability [113]. The flow time of RHA mortar obtained from the mini V-funnel test increased by $12.5 \%-37.5 \%$ when $5 \%-20 \%$ RHA was used with the same SP dosage; however, the flow spread was not significantly different from that of the control mortar including $100 \%$ OPC [113] due to the increased paste volume resulting from the lower specific gravity of RHA (refer to Table 2) that enhanced the dispersion of fine aggregate particles. Self-compacting mortar can be produced using 5\%-30\% RHA with high-range water-reducing and viscosity-modifying admixtures at a relatively low $\mathrm{w} / \mathrm{b}$ ratio $[113,123]$.

\subsubsection{Effects on Strength}

Coarse RHA may decrease the compressive strength of mortar owing to larger and porous particles. An increase in coarse RHA content from 5\% to 20\% caused a decrease in strength of 37\% after 90 days, with more influence at early ages [113]. The burning temperature of rice husks and the particle size of RHA influence the strength performance of RHA mortar. In the study by Antiohos et al. [79], the lower burning temperature (by approximately $50{ }^{\circ} \mathrm{C}$ ) resulted in higher amorphous silica content (by nearly $7 \%$ ). This extra silica helped to gain more strength at all ages for $10 \%-30 \%$ RHA. Antiohos et al. [79] reported that the RHA particles with a Blaine fineness of $4000 \mathrm{~cm}^{2} / \mathrm{g}$ could only be considered beneficial for the strength of mortar after 28 days; further grinding to the Blaine fineness of $7000 \mathrm{~cm}^{2} / \mathrm{g}$ improves the performance of RHA substantially [79]. In this study, the RHA that was burnt at a lower temperature and ground to $7000 \mathrm{~cm}^{2} / \mathrm{g}$ exhibited an equivalent strength profile of CEM-I $42.5 \mathrm{~N}$, up to a replacement level of $10 \%$. Higher replacements produced a slightly lower strength; at 28 days, $30 \%$ RHA provided $48.8 \mathrm{MPa}$ compressive strength, which is $89.4 \%$ of the strength of the control mortar [79]. The second time burning improves the quality of RHA, which can provide $20 \%-25 \%$ higher strength than OPC alone; a secondary heat treatment at $650{ }^{\circ} \mathrm{C}$ for $1 \mathrm{~h}\left(200{ }^{\circ} \mathrm{C}\right.$ per hour rate of increase) and a subsequent pulverization to a mean grain size of $3.8 \mu \mathrm{m}$ produce the RHA, which demonstrates the equivalent compressive strength of OPC at $30 \%$ content at all ages; the mortar with $15 \%$ such RHA had the best strength which is $46.7 \mathrm{MPa}$, compared to the $37 \mathrm{MPa}$ compressive strength of the control mortar [78]. In another study, rice husks were burnt at $600{ }^{\circ} \mathrm{C}$ for $4 \mathrm{~h}$ and then at 
$700{ }^{\circ} \mathrm{C}$ for $3 \mathrm{~h}$. The mortar samples containing this RHA as $10 \%-30 \%$ cement substitutions provided approximately $20 \%$ more compressive strength at 28 days [80]. A theoretical model suggests that the optimum content of RHA without any non-reactive silica is nearly $14.3 \%$ for a cementitious system (e.g., cement mortar) containing ASTM Type I cement [172].

\subsubsection{Effects on Durability and Other Properties}

By its pozzolanic and micro-filling effects, RHA increases the nucleation sites and the strengthcontributing hydration product, reducing $\mathrm{Ca}(\mathrm{OH})_{2}$ concentration and porosity. As a result, water absorption, water permeability, and chloride ion penetration are reduced, and electrical resistivity is increased with an increase in RHA content. The degree of improvement depends on the replacement ratio, particle size, and treatment procedure of RHA. Only 10\% RHA, which has gone through a secondary burning, can reduce the rapid chloride penetration (RCP) level from "moderate" to "very low" [80,168]. The use of 40\% RHA resulted in a drop from 7500 Coulombs to only 200 Coulombs of RCP value at 28 days [90]. Even without a secondary burning, depending on the source, the RHA of $4000 \mathrm{~cm}^{2} / \mathrm{g}$ Blaine fineness maintained an RCP level of "low" or "very low" for the RHA mortar just after 55 days, while the control mortar was in "moderate" range [79]. A similar trend was observed for electrical resistivity, which showed a strong correlation with RCP. The electrical resistivity of mortar increased with the incorporation of RHA; 30\% RHA provided 12 times more resistivity than the control mortar [80]. Moreover, the pozzolanic reaction causes a drop in the amount of $\mathrm{Ca}(\mathrm{OH})_{2}$ in mortar and thus creates denser C-S-H gel. Thus, the inclusion of RHA enhances the resistance of mortar against acid attack. The mortar made with 10\%-30\% RHA had significantly better performance when exposed to nitric and acetic acids, in terms of residual strength, mass loss, and length change. After 90 days of exposure to nitric or acetic acid, the mortar samples prepared with a w/b ratio of 0.55 and $10 \%$ RHA retained $30-33 \mathrm{MPa}$ compressive strength, which is $67 \%-72 \%$ of the original strength $(46 \mathrm{MPa})$, while the mortar samples without RHA could retain only $50 \%-62 \%$ of their strength. The mass loss and length change also followed a similar trend [81]. Moreover, an increase in the resistance of mortar against sulphate attack was reported in one study [158].

\subsection{Waste Glass Powder (WGP)}

\subsubsection{Effects on Flowability}

Since the glass waste residue has a high specific surface area or surface fineness (Blaine fineness of $477 \mathrm{~m}^{2} / \mathrm{kg}$ ), the partial replacement of cement with WGP increases the water consumption. Thus, an increasing trend of SP requirement was observed as the percentage of cement replacement increased; the mortar with 20\% WGP consumed as much as 2.7 times SP for the same consistency of the control mortar with 100\% OPC [85]. Because of higher water demand, a mortar including WGP exhibits lower flowability. The flow spread of the mortar containing 25\% WGP was $205 \mathrm{~mm}$, whereas the OPC mortar had a flow spread of $220 \mathrm{~mm}$ [20].

\subsubsection{Effects on Strength}

High silica and alumina contents of WGP lead to a good pozzolanic reactivity. Hence, the compressive strength increases when WGP is used in a cementitious mixture. Parghi and Alam [20] reported a gain in the compressive strength of cement composite for up to $25 \%$ WGP. The use of $25 \%$ WGP provided 30\% and 40\% more strength at 28 and 90 days, respectively, over the control mortar without any WGP [20]. Calmon et al. [85] found a different trend for the strength properties of mortar containing WGP. In their study, after 270 days, the mortar with only 5\% WGP provided a compressive strength which is higher (about 6\%) than the strength of the control mortar without any WGP; but higher substitution led to lower compressive strength; however, up to $20 \%$ replacement, every mortar reached at least $30 \mathrm{MPa}$ compressive strength at the age of 28 days. They stated that the presence of $\mathrm{Al}_{2} \mathrm{O}_{3}$ and $\mathrm{Na}_{2} \mathrm{O}$ at a content higher than the permissible limit (5\% and 1.5\%, respectively) may cause 
the formation of expansive compounds (e.g., delayed ettringite), which may decrease the compressive strength of mortar [85]. Matos and Sousa-Coutinho [84] also reported inferior compressive strength values for $10 \%$ and $20 \%$ WGP at 28 days although both contents provided a strength value ( $54 \mathrm{MPa}$ ) like that of OPC mortar at 90 days. Conversely, a significant improvement in the tensile bond strength was observed in the presence of WGP; the mortars with $10 \%$ and $20 \%$ WGP resulted in $280 \%$ and $170 \%$ higher tensile bond strength, respectively, than the control mortar [85].

The particle size distribution plays a significant role in the performance of WGP as a partial replacement of cement. The lower the particle size, the higher is the reaction rate. WGP possessing particles in the size range of 0-25 $\mu \mathrm{m}$ shows pozzolanic activity just after 7 days, while 25-38 $\mu \mathrm{m}$ and 63-75 $\mu \mathrm{m}$ size ranges show this activity only after 28 days at $50{ }^{\circ} \mathrm{C}$. A reduction in the particle size of WGP results in more and denser secondary $\mathrm{C}-\mathrm{S}-\mathrm{H}$, thus higher strength. When the WGP with 0-25 $\mu \mathrm{m}$ size distribution was used, $\mathrm{Ca}(\mathrm{OH})_{2}$ content was depleted 1.5 and 2.3 times more than the size ranges of $25-38 \mu \mathrm{m}$ and $63-75 \mu \mathrm{m}$, respectively [173]. According to the activation energy values, WGP could be classified as a moderately temperature-dependent SCM. The growth in reaction rate and the reduction in portlandite content as much as $100 \%$ and $30 \%$, respectively, were reported at elevated temperatures compared to low temperatures [115]. The mortar samples containing WGP did not show any significant pozzolanic reaction at $23^{\circ} \mathrm{C}$ even at the age of 91 days. Rather it resulted in lower strength due to higher effective $\mathrm{w} / \mathrm{b}$ ratio. The WGP with $0-25 \mu \mathrm{m}$ size distribution showed $21 \%$ higher reactivity at $50^{\circ} \mathrm{C}$ than $10^{\circ} \mathrm{C}$ and $23^{\circ} \mathrm{C}$. The mortar including WGP in $63-75 \mu \mathrm{m}$ size range also had $30 \%$ less portlandite content than the control mortar at 28 and 91 days; however, no pozzolanic reactivity was observed for this WGP mortar at $23{ }^{\circ} \mathrm{C}$ even at 91 days [173]. At a $\mathrm{pH}$ level higher than 12.5 , green-colored glass liberates more silica and alumina ions than clear glass; therefore, the mortar containing green WGP achieves higher strength than the control mortar and the mortar including clear WGP just after 7 days at $50^{\circ} \mathrm{C}$; at this temperature, the mortar including green WGP gained more than $40 \mathrm{MPa}$ compressive strength, which was 30\% higher than the strength of the other two mortars [86].

\subsubsection{Effects on Durability and Other Properties}

The mortar with $10 \%$ WGP showed a much better resistance against sulphate attack compared with the mortar including an equal amount of SF and the control mortar (100\% OPC), showing almost zero expansion even after 26 weeks; the pozzolanic activity of WGP binds portlandite, which is released during the hydration of calcium silicates $\left(C_{2} S\right.$ and $\left.C_{3} S\right)$, making it unavailable for reaction with sulphates $[84,152]$. The chloride penetration is also minimized in the presence of WGP. The mortar with $20 \%$ WGP had only $7.8 \times 10^{-12} \mathrm{~m}^{2} / \mathrm{s}$ chloride diffusion coefficient whereas the OPC mortar gave a chloride diffusion coefficient of $16.2 \times 10^{-12} \mathrm{~m}^{2} / \mathrm{s}$ [84]. In contrast, WGP is not effective in reducing the permeation of $\mathrm{CO}_{2}$ into mortar; the mortar containing WGP had a larger carbonation depth than the control mortar; however, it was significantly lower than that of SF mortar for $10 \%$ replacement of cement after 2 months water curing at $20^{\circ} \mathrm{C}$ followed by 4 months exposure to $5 \pm 0.1 \% \mathrm{CO}_{2}$ in an accelerated carbonation chamber [84].

WGP is better able to fill in the pores by denser hydration products at later ages at elevated temperatures because of its slower reactivity than cement; hence, the mortar samples with WGP possessed less porosity than the control samples at later ages at $50^{\circ} \mathrm{C}$ and therefore they exhibited lower water absorptivity [115]. With higher pozzolanic reactivity, green WGP decreased water absorption more than clear WGP [86]. The water absorption depth of the mortar incorporating green WGP in the size range of $0-25 \mu \mathrm{m}$ was less than $1 \mathrm{~mm}$ at 91 days and $50{ }^{\circ} \mathrm{C}$, whereas it was above $1.5 \mathrm{~mm}$ for the control mortar [86]. In another study, the capillary water absorption of the mortar with $15 \%$ WGP was 33\% lower than that of OPC mortar, where $98 \%$ of the WGP particles was under $75 \mu \mathrm{m}$ in size [85]. Moreover, the reactive silica from WGP dissolves during the pozzolanic reaction and forms the mineral phases of cementitious compounds. Therefore, the reactive silica of WGP will be unavailable for ASR at later ages [118]. Thus, an increased WGP content decreases ASR expansion, despite its considerable alkali content; the mortar samples with 10\% WGP showed ASR expansion 
less than that of the OPC mortar samples but still failed to reach the recommended safe level [84,152]; however, $20 \%$ WGP dropped the expansion to $0.041 \%$ [84], which is much lower than the critical level of $0.1 \%$ given in ASTM C1567 [169]. These findings suggest that, to avoid ASR, the quantity of WGP should be optimized to use up all reactive silica and moisture during the pozzolanic reaction with $\mathrm{Ca}(\mathrm{OH})_{2}$. Nevertheless, it should be kept in mind that the increased amount of WGP may increase the drying shrinkage of mortar; the greater the substitution level of OPC by WGP, the higher is the drying shrinkage value of mortar; at 63 days, the drying shrinkage value of the mortar including $20 \%$ WGP was $16 \%$ higher than that of the control mortar [85].

\section{Contributions of SCMs and Structural Mortar to Sustainable Construction}

The goal of sustainable development in the built environment is to minimize the consumption of natural resources and to minimize waste generation. SCMs provide construction practitioners the liberty to prepare structural mortar with less cement, which can be used as concrete repair material, rendering material in retrofitting works, and equivalent concrete mortar for designing high performance concrete. An effective repair or retrofitting system can elevate the structural condition consuming fewer natural resources and generating almost zero waste compared to demolition and reconstruction. Besides, the utilization of by-products or wastes in cementitious mixture prevents their disposal in nature and decreases the depletion of natural clinker and fossil fuel to produce cement, resulting in a substantial reduction in greenhouse gas emissions to the atmosphere, thus contributing to environmental sustainability. Most of the SCMs have much lower carbon footprint compared to OPC. For instance, OPC, FA, GGBS, and LP release greenhouse gases equivalent to 860, 0.1, 79.6, and $8 \mathrm{~kg} \mathrm{CO}_{2}$ per ton, respectively [174]. The carbon footprints of the cement blends using these SCMs at a proportion recommended in BS 8500-1 are given in Table 6. This table shows that, although FA has the lowest carbon footprint, GGBS makes the cement blend with the lowest greenhouse gas emissions, as it is allowed for use up to $80 \%$ [175]. Reducing resource consumption and waste generation as well as preventing hazardous chemical disposal in nature, structural mortar made with SCM can take one step forward to sustainable construction.

Table 6. Greenhouse gas generation (as equivalent $\mathrm{CO}_{2}$ ) by the factory-made cement types [174].

\begin{tabular}{ccc}
\hline Cement Designation [175] & SCM Content & Equivalent $\mathbf{C O}_{\mathbf{2}}$ (kg/ton) \\
\hline CEM I & $0 \%$ & 860 \\
CEM II/A-LL or L & $6 \%-20 \%$ LP & $842-721$ \\
CEM II/A-V & $6 \%-20 \%$ FA & $825-686$ \\
CEM II/B-V & $21 \%-35 \%$ FA & $694-555$ \\
CEM II/B-S & $21 \%-35 \%$ GGBS & $712-585$ \\
CEM III/A & $36 \%-65 \%$ GGBS & $594-350$ \\
CEM III/B & $66 \%-80 \%$ GGBS & $359-232$ \\
CEM IV/B-V & $36 \%-55 \%$ FA & $564-381$ \\
\hline
\end{tabular}

\section{Research Gaps and Recommendations}

The research gaps that have been identified based on the comprehensive review conducted by the authors of the present study are given below. Along with the research gaps, several specific recommendations are also given for further research.

- Some treatments (e.g., controlled burning and/or grinding) substantially improve SCM properties. The effects of such treatment processes on most SCMs were not studied thoroughly. The optimum treatment process needs to be determined for each SCM, especially for those obtained from agricultural sources.

- Different researchers experimented in different conditions for very specific purposes. Comparing SCMs for use in construction is difficult based on these situation-dependent data. The detailed characterization of each widely available SCM should be accomplished. 
- Studies on how the behavior of SCM changes with its source and application conditions are still inadequate. The behavior of SCM incorporated mortars in every real-life situation (e.g., frost, high temperature, impact loading, exposure to seawater, etc.) should be determined.

- The effects of VA on the flowability of mortar mixture and its resistance against carbonation, acid attack, sulphate attack, and freezing and thawing are unknown. Therefore, broad research should be carried out to study these properties of VA mortar.

- The durability performance of BA mortar needs to be investigated thoroughly. Especially, the ASR resistance of BA mortar is very important, as some studies reported the signs of ASR due to the high concentration of $\mathrm{K}^{+}$ions released from BA.

- RHA mortar should be investigated for its resistance against carbonation, ASR, sulphate attack, and freezing and thawing.

- The applications of POFA and GGBS as an SCM in mortar should be explored by examining their resistance against carbonation, acid attack, ASR, and freezing and thawing. Especially, the high content of $\mathrm{K}_{2} \mathrm{O}$ in POFA raises a concern about ASR.

- The behavior in acidic and freeze-thaw environments are still unexplored for the mortars containing LP and WGP. In addition, the influence of LP on ASR and chloride penetration needs broad investigation.

- The resistance of FA mortar against carbonation and acid attack needs to be examined systematically.

- Studies on the use of SCMs in structural mortar at different multilevel combinations, such as binary and ternary levels, were not performed meticulously.

- Dependable analytical models for predicting the effects of SCM on the mortar-performance are absent. Such models should be established considering all influencing parameters to predict the consequences of SCM inclusion.

- The carbon footprints of the mortars made with blended cement types, including various SCMs need to be determined.

- To ensure sustainable development, the total impact of the SCM incorporated structural mortar on the environment and economy should be quantified in a holistic manner, considering the treatment process, replacement level, and durability.

- To avoid contamination, the leaching of heavy metals from the cementitious products containing SCM should be quantified before any industrial application.

\section{Concluding Remarks}

Like all other industries, the construction industry is also looking for eco-friendly strategies. Cement is one of the main ingredients of construction. The production of cement is an energy- and carbon-intensive process. Many industrial by-products, several materials obtained from agricultural and municipal wastes, and some materials found from natural sources have shown promising performance as SCMs, when used as a partial replacement of cement in structural mortar. In many cases, the use of such by-products or wastes supersedes the sole performance of cement. Furthermore, such utilization can reduce the consumption of natural resources and the production cost in cement factories, as well as ensure the proper management of by-products or wastes. However, effective utilization of SCMs demands more intensive studies. A holistic study of SCM properties and their effects on the end products under different conditions is required for efficient environmental management, as well as to further optimize the desired engineering performance of structural mortar for sustainable construction.

Author Contributions: S.N.R., A.B.M.A.K. and S.S. designed the research program. The data collection, assessment, and analysis were performed by S.S. under the guidance and supervision of S.N.R., A.B.M.A.K. and A.A.M. M.S. significantly assisted in the analysis of research findings to facilitate the present study. The manuscript was written by S.S. and S.N.R. and was supplemented by the contributions of M.S., A.B.M.A.K. and A.A.M. M.S. critically 
reviewed the paper and provided valuable technical inputs to improve its overall quality. All authors have read and agreed to the published version of the manuscript.

Funding: This research was funded by the Ministry of Higher Education, Malaysia through the Fundamental Research Grant Scheme (FRGS/1/2019/TK01/UKM/02/2).

Acknowledgments: Ministry of Higher Education, Malaysia and Universiti Kebangsaan Malaysia (UKM).

Conflicts of Interest: The authors declare no conflict of interest.

\section{References}

1. Halada, K. Progress of ecomaterials toward a sustainable society. Curr. Opin. Solid State Mater. Sci. 2003, 7, 209-216. [CrossRef]

2. CEMBUREAU (The European Cement Association). Activity Report 2015; The European Cement Association: Brussels, Belgium, 2016.

3. Tamanna, K.; Raman, S.N.; Jamil, M.; Hamid, R. Utilization of wood waste ash in construction technology: A review. Constr. Build. Mater. 2020, 237, 117654. [CrossRef]

4. Khan, M.N.N.; Jamil, M.; Karim, M.R.; Zain, M.F.M.; Kaish, A.B.M.A. Filler effect of pozzolanic materials on the strength and microstructure development of mortar. KSCE J. Civ. Eng. 2017, 21, 274-284. [CrossRef]

5. Celik, K.; Jackson, M.D.; Mancio, M.; Meral, C.; Emwas, A.H.; Mehta, P.K.; Monteiro, P.J.M. High-volume natural volcanic pozzolan and limestone powder as partial replacements for portland cement in self-compacting and sustainable concrete. Cem. Concr. Compos. 2014, 45, 136-147. [CrossRef]

6. CEMBUREAU. Cement 101: Key Facts \& Figures. Available online: https://cembureau.eu/cement-101/keyfacts-figures/ (accessed on 29 July 2017).

7. Shubbar, A.A.; Jafer, H.; Abdulredha, M.; Al-khafaji, Z.S.; Nasr, M.S.; Al Masoodi, Z.; Sadique, M. Properties of cement mortar incorporated high volume fraction of GGBFS and CKD from 1 day to 550 days. J. Build. Eng. 2020, 30, 101327. [CrossRef]

8. Teixeira, E.R.; Mateus, R.; Camões, A.; Branco, F.G. Quality and durability properties and life-cycle assessment of high volume biomass fly ash mortar. Constr. Build. Mater. 2019, 197, 195-207. [CrossRef]

9. WBCSD-CSI (World Business Council for Sustainable Development-Cement Sustainability Initiative. $\mathrm{CO}_{2}$ and Climate Protection. Available online: http://www.wbcsdcement.org/index.php/key-issues/climate-protection (accessed on 31 March 2017).

10. Tosti, L.; van Zomeren, A.; Pels, J.R.; Comans, R.N.J. Technical and environmental performance of lower carbon footprint cement mortars containing biomass fly ash as a secondary cementitious material. Resour. Conserv. Recycl. 2018, 134, 25-33. [CrossRef]

11. UNFCCC (United Nations Framework Convention on Climate Change). Adoption of the Paris Agreement, FCCC/CP/2015/L.9/Rev.1. In Proceedings of the Conference Parties on Its Twenty First Session, Paris, France, 30 November-11 December 2015.

12. UNFCCC (United Nations Framework Convention on Climate Change). Paris Agreement-Status of Ratification. Available online: http://unfccc.int/paris_agreement/items/9444.php (accessed on 5 July 2017).

13. ASTM C219-14a. Standard Terminology Relating to Hydraulic Cement; ASTM International: West Conshohocken, PA, USA, 2014.

14. Papayianni, I.; Karaveziroglou, M.; Athanassiou, F.; Georgisoudi, K.; Revithiadou, K. Mortars used for intervention in archaeological site of Ancient Olynthos. Trans. Built Environ. 1995, 15, 223-230.

15. ASTM C270-14a. Standard Specification for Mortar for Unit Masonry; ASTM International: West Conshohocken, PA, USA, 2014.

16. EN 1504-3. Products and systems for the protection and repair of concrete structures- Definitions, requirements, quality control and evaluation of conformity. In Part 3: Structural and Non-Structural Repair; CEN (European Committee for Standardization): Brussels, Belgium, 2006.

17. FDOT (Florida Department of Transportation). Materials for concrete repair. In Standard Specifications for Road and Bridge Construction; FDOT: Tallahassee, FL, USA, 2017; Section 930; pp. 1069-1075.

18. ACI 549.1R-93. Guide for the Design, Construction and Repair of Ferrocement; American Concrete Institute (ACI): Farmington Hills, MI, USA, 1993.

19. Rao, S.; Silva, P.; de Brito, J. Experimental study of the mechanical properties and durability of self-compacting mortars with nano materials $\left(\mathrm{SiO}_{2}\right.$ and $\left.\mathrm{TiO}_{2}\right)$. Constr. Build. Mater. 2015, 96, 508-517. [CrossRef] 
20. Parghi, A.; Alam, M.S. Physical and mechanical properties of cementitious composites containing recycled glass powder (RGP) and styrene butadiene rubber (SBR). Constr. Build. Mater. 2016, 104, 34-43. [CrossRef]

21. Sigvardsen, N.M.; Ottosen, L.M. Characterization of coal bio ash from wood pellets and low-alkali coal fly ash and use as partial cement replacement in mortar. Cem. Concr. Compos. 2019, 95, 25-32. [CrossRef]

22. Hsu, S.; Chi, M.; Huang, R. Effect of fineness and replacement ratio of ground fly ash on properties of blended cement mortar. Constr. Build. Mater. 2018, 176, 250-258. [CrossRef]

23. Wongkeo, W.; Thongsanitgarn, P.; Ngamjarurojana, A.; Chaipanich, A. Compressive strength and chloride resistance of self-compacting concrete containing high level fly ash and silica fume. Mater. Des. 2014, 64, 261-269. [CrossRef]

24. Supit, S.W.M.; Shaikh, F.U.A.; Sarker, P.K. Effect of ultrafine fly ash on mechanical properties of high volume fly ash mortar. Constr. Build. Mater. 2014, 51, 278-286. [CrossRef]

25. Antoni; Chandra, L.; Hardjito, D. The impact of using fly ash, silica fume and calcium carbonate on the workability and compressive strength of mortar. Procedia Eng. 2015, 125, 773-779. [CrossRef]

26. Turk, K. Viscosity and hardened properties of self-compacting mortars with binary and ternary cementitious blends of fly ash and silica fume. Constr. Build. Mater. 2012, 37, 326-334. [CrossRef]

27. Lee, N.K.; Jang, J.G.; Lee, H.K. Shrinkage characteristics of alkali-activated fly ash/slag paste and mortar at early ages. Cem. Concr. Compos. 2014, 53, 239-248. [CrossRef]

28. Soriano, L.; Payá, J.; Monzó, J.; Borrachero, M.V.; Tashima, M.M. High strength mortars using ordinary Portland cement-fly ash-fluid catalytic cracking catalyst residue ternary system (OPC/FA/FCC). Constr. Build. Mater. 2016, 106, 228-235. [CrossRef]

29. Arenas-Piedrahita, J.C.; Montes-García, P.; Mendoza-Rangel, J.M.; López Calvo, H.Z.; Valdez-Tamez, P.L.; Martínez-Reyes, J. Mechanical and durability properties of mortars prepared with untreated sugarcane bagasse ash and untreated fly ash. Constr. Build. Mater. 2016, 105, 69-81. [CrossRef]

30. Kondraivendhan, B.; Bhattacharjee, B. Flow behavior and strength for fly ash blended cement paste and mortar. Int. J. Sustain. Built Environ. 2015, 4, 270-277. [CrossRef]

31. Cheng, A. Effect of incinerator bottom ash properties on mechanical and pore size of blended cement mortars. Mater. Des. 2012, 36, 859-864. [CrossRef]

32. Oruji, S.; Brake, N.A.; Nalluri, L.; Guduru, R.K. Strength activity and microstructure of blended ultra-fine coal bottom ash-cement mortar. Constr. Build. Mater. 2017, 153, 317-326. [CrossRef]

33. Rosales, J.; Cabrera, M.; Beltrán, M.G.; López, M.; Agrela, F. Effects of treatments on biomass bottom ash applied to the manufacture of cement mortars. J. Clean. Prod. 2017, 154, 424-435. [CrossRef]

34. Menéndez, E.; Álvaro, A.M.; Hernández, M.T.; Parra, J.L. New methodology for assessing the environmental burden of cement mortars with partial replacement of coal bottom ash and fly ash. J. Environ. Manag. 2014, 133, 275-283. [CrossRef] [PubMed]

35. Maschio, S.; Tonello, G.; Piani, L.; Furlani, E. Fly and bottom ashes from biomass combustion as cement replacing components in mortars production: Rheological behaviour of the pastes and materials compression strength. Chemosphere 2011, 85, 666-671. [CrossRef]

36. Jang, J.G.; Kim, H.J.; Kim, H.K.; Lee, H.K. Resistance of coal bottom ash mortar against the coupled deterioration of carbonation and chloride penetration. Mater. Des. 2016, 93, 160-167. [CrossRef]

37. Kim, H.K. Utilization of sieved and ground coal bottom ash powders as a coarse binder in high-strength mortar to improve workability. Constr. Build. Mater. 2015, 91, 57-64. [CrossRef]

38. Sumesh, M.; Alengaram, U.J.; Jumaat, M.Z.; Mo, K.H. Microstructural and strength characteristics of high-strength mortar using nontraditional supplementary cementitious materials. J. Mater. Civ. Eng. 2019, 31, 04019017. [CrossRef]

39. Hot, J.; Cyr, M.; Augeard, E.; Eekhout, M. An investigation of CaSi silica fume characteristics and its possible utilization in cement-based and alkali-activated materials. Constr. Build. Mater. 2015, 101, 456-465. [CrossRef]

40. Dawood, E.T.; Ramli, M. Development of high strength flowable mortar with hybrid fiber. Constr. Build. Mater. 2010, 24, 1043-1050. [CrossRef]

41. Senhadji, Y.; Escadeillas, G.; Mouli, M.; Khelafi, H. Benosman Influence of natural pozzolan, silica fume and limestone fine on strength, acid resistance and microstructure of mortar. Powder Technol. 2014, 254, 314-323. [CrossRef] 
42. Qing, Y.; Zenan, Z.; Deyu, K.; Rongshen, C. Influence of nano-SiO 2 addition on properties of hardened cement paste as compared with silica fume. Constr. Build. Mater. 2007, 21, 539-545. [CrossRef]

43. Mardani-Aghabaglou, A.; İnan Sezer, G.; Ramyar, K. Comparison of fly ash, silica fume and metakaolin from mechanical properties and durability performance of mortar mixtures viewpoints. Constr. Build. Mater. 2014, 70, 17-25. [CrossRef]

44. Rossen, J.E.; Lothenbach, B.; Scrivener, K.L. Composition of C-S-H in pastes with increasing levels of silica fume addition. Cem. Concr. Res. 2015, 75, 14-22. [CrossRef]

45. Liu, J.; Li, Y.; Ouyang, P.; Yang, Y. Hydration of the silica fume-Portland cement binary system at lower temperature. Constr. Build. Mater. 2015, 93, 919-925. [CrossRef]

46. Inan Sezer, G. Compressive strength and sulfate resistance of limestone and/or silica fume mortars. Constr. Build. Mater. 2012, 26, 613-618. [CrossRef]

47. Koksal, F.; Gencel, O.; Kaya, M. Combined effect of silica fume and expanded vermiculite on properties of lightweight mortars at ambient and elevated temperatures. Constr. Build. Mater. 2015, 88, 175-187. [CrossRef]

48. Kırca, Ö.; Özgür Yaman, İ.; Tokyay, M. Compressive strength development of calcium aluminate cement-GGBFS blends. Cem. Concr. Compos. 2013, 35, 163-170. [CrossRef]

49. Kuo, W.T.; Chen, S.H.; Wang, H.Y.; Lin, J.C. A study on the mechanical and electricity properties of cement mortar added with GGBFS and piezoelectric powder. Constr. Build. Mater. 2013, 49, 251-256. [CrossRef]

50. Memon, N.A.; Sumadi, S.R.; Ramli, M. Performance of high workability slag-cement mortar for ferrocement. Build. Environ. 2007, 42, 2710-2717. [CrossRef]

51. Sakir, S.; Kaish, A.B.M.A.; Raman, S.; Mutalib, A. Recent trends in development of self-flowing mortar incorporating supplementary cementitious materials. In Proceedings of the 2nd International Electronic Conference on Materials, 2-16 May 2016; MDPI: Basel, Switzerland, 2016; Volume 2, p. 001.

52. Lomboy, G.; Sundararajan, S.; Wang, K.; Subramaniam, S. A test method for determining adhesion forces and Hamaker constants of cementitious materials using atomic force microscopy. Cem. Concr. Res. 2011, 41, 1157-1166. [CrossRef]

53. Onn, C.C.; Mo, K.H.; Radwan, M.K.H.; Liew, W.H.; Ng, C.G.; Yusof, S. Strength, carbon footprint and cost considerations of mortar blends with high volume ground granulated blast furnace slag. Sustainability 2019, 11, 7194. [CrossRef]

54. Shubbar, A.A.; Al-Shaer, A.; AlKizwini, R.S.; Hashim, K.; Hawesah, H.A.; Sadique, M. Investigating the influence of cement replacement by high volume of GGBS and PFA on the mechanical performance of cement mortar. In Proceedings of the International Conference on Civil and Environmental Engineering Technologies, Najaf, Iraq, 23-24 April 2019; IOP Publishing: Bristol, UK, 2019; Volume 584, p. 012022.

55. Benabed, B.; Kadri, E.H.; Azzouz, L.; Kenai, S. Properties of self-compacting mortar made with various types of sand. Cem. Concr. Compos. 2012, 34, 1167-1173. [CrossRef]

56. Silva, P.R.D.; de Brito, J. Fresh-state properties of self-compacting mortar and concrete with combined use of limestone filler and fly ash. Mater. Res. 2015, 18, 1097-1108. [CrossRef]

57. Rizwan, S.A.; Bier, T.A. Blends of limestone powder and fly-ash enhance the response of self-compacting mortars. Constr. Build. Mater. 2012, 27, 398-403. [CrossRef]

58. Shi, Z.; Lothenbach, B.; Geiker, M.R.; Kaufmann, J.; Leemann, A.; Ferreiro, S.; Skibsted, J. Experimental studies and thermodynamic modeling of the carbonation of Portland cement, metakaolin and limestone mortars. Cem. Concr. Res. 2016, 88, 60-72. [CrossRef]

59. Makhloufi, Z.; Chettih, M.; Bederina, M.; Kadri, E.L.H.; Bouhicha, M. Effect of quaternary cementitious systems containing limestone, blast furnace slag and natural pozzolan on mechanical behavior of limestone mortars. Constr. Build. Mater. 2015, 95, 647-657. [CrossRef]

60. Ezziane, K.; Kadri, E.-H.H.; Bougara, A.; Bennacer, R. Analysis of mortar long-term strength with supplementary cementitious materials cured at different temperatures. ACI Mater. J. 2010, 107, 323-331.

61. Deboucha, W.; Leklou, N.; Khelidj, A.; Plé, O.; Alengaram, U.J. Combination effect of limestone filler and slag on delayed ettringite formation in heat-cured mortar. J. Mater. Civ. Eng. 2020, 32, 04019365. [CrossRef]

62. Celik, K.; Hay, R.; Hargis, C.W.; Moon, J. Effect of volcanic ash pozzolan or limestone replacement on hydration of Portland cement. Constr. Build. Mater. 2019, 197, 803-812. [CrossRef] 
63. Vejmelková, E.; Pavlíková, M.; Keppert, M.; Keršner, Z.; Rovnaníková, P.; Ondráček, M.; Sedlmajer, M.; Černý, R. High performance concrete with Czech metakaolin: Experimental analysis of strength, toughness and durability characteristics. Constr. Build. Mater. 2010, 24, 1404-1411. [CrossRef]

64. Mehdipour, I.; Vahdani, M.; Amini, K.; Shekarchi, M. Linking stability characteristics to material performance of self-consolidating concrete-equivalent-mortar incorporating fly ash and metakaolin. Constr. Build. Mater. 2016, 105, 206-217. [CrossRef]

65. Cassagnabère, F.; Diederich, P.; Mouret, M.; Escadeillas, G.; Lachemi, M. Impact of metakaolin characteristics on the rheological properties of mortar in the fresh state. Cem. Concr. Compos. 2013, 37, 95-107. [CrossRef]

66. Jiang, G.; Rong, Z.; Sun, W. Effects of metakaolin on mechanical properties, pore structure and hydration heat of mortars at $0.17 \mathrm{w} / \mathrm{b}$ ratio. Constr. Build. Mater. 2015, 93, 564-572. [CrossRef]

67. Nadeem, A.; Memon, S.A.; Lo, T.Y. Mechanical performance, durability, qualitative and quantitative analysis of microstructure of fly ash and Metakaolin mortar at elevated temperatures. Constr. Build. Mater. 2013, 38, 338-347. [CrossRef]

68. Al-Fadala, S.; Chakkamalayath, J.; Al-Bahar, S.; Al-Aibani, A.; Ahmed, S. Significance of performance based specifications in the qualification and characterization of blended cement using volcanic ash. Constr. Build. Mater. 2017, 144, 532-540. [CrossRef]

69. Diaz-Loya, I.; Juenger, M.; Seraj, S.; Minkara, R. Extending supplementary cementitious material resources: Reclaimed and remediated fly ash and natural pozzolans. Cem. Concr. Compos. 2017, 101, 44-51. [CrossRef]

70. Hossain, K.M.A.; Lachemi, M. Corrosion resistance and chloride diffusivity of volcanic ash blended cement mortar. Cem. Concr. Res. 2004, 34, 695-702. [CrossRef]

71. Hossain, K.M.A. Blended cement using volcanic ash and pumice. Cem. Concr. Res. 2003, 33, 1601-1605. [CrossRef]

72. Hassan, I.O.; Ismail, M.; Forouzani, P.; Majid, Z.A.; Mirza, J. Flow characteristics of ternary blended self-consolidating cement mortars incorporating palm oil fuel ash and pulverised burnt clay. Constr. Build. Mater. 2014, 64, 253-260. [CrossRef]

73. Bamaga, S.O.; Ismail, M.A.; Majid, Z.A.; Ismail, M.; Hussin, M.W. Evaluation of sulfate resistance of mortar containing palm oil fuel ash from different sources. Arab. J. Sci. Eng. 2013, 38, 2293-2301. [CrossRef]

74. Lim, N.H.A.S.; Ismail, M.A.; Lee, H.S.; Hussin, M.W.; Sam, A.R.M.; Samadi, M. The effects of high volume nano palm oil fuel ash on microstructure properties and hydration temperature of mortar. Constr. Build. Mater. 2015, 93, 29-34. [CrossRef]

75. Chandara, C.; Mohd Azizli, K.A.; Ahmad, Z.A.; Saiyid Hashim, S.F.; Sakai, E. Heat of hydration of blended cement containing treated ground palm oil fuel ash. Constr. Build. Mater. 2012, 27, 78-81. [CrossRef]

76. Farzadnia, N.; Noorvand, H.; Yasin, A.M.; Aziz, F.N. The effect of nano silica on short term drying shrinkage of POFA cement mortars. Constr. Build. Mater. 2015, 95, 636-646. [CrossRef]

77. Jaturapitakkul, C.; Tangpagasit, J.; Songmue, S.; Kiattikomol, K. Filler effect and pozzolanic reaction of ground palm oil fuel ash. Constr. Build. Mater. 2011, 25, 4287-4293. [CrossRef]

78. Ganesan, K.; Rajagopal, K.; Thangavel, K. Rice husk ash blended cement: Assessment of optimal level of replacement for strength and permeability properties of concrete. Constr. Build. Mater. 2008, 22, 1675-1683. [CrossRef]

79. Antiohos, S.K.; Papadakis, V.G.; Tsimas, S. Rice husk ash (RHA) effectiveness in cement and concrete as a function of reactive silica and fineness. Cem. Concr. Res. 2014, 61-62, 20-27. [CrossRef]

80. Zunino, F.; Lopez, M. Decoupling the physical and chemical effects of supplementary cementitious materials on strength and permeability: A multi-level approach. Cem. Concr. Compos. 2016, 65, 19-28. [CrossRef]

81. Chatveera, B.; Lertwattanaruk, P. Evaluation of nitric and acetic acid resistance of cement mortars containing high-volume black rice husk ash. J. Environ. Manag. 2014, 133, 365-373. [CrossRef]

82. Lim, J.L.G.; Raman, S.N.; Lai, F.-C.; Zain, M.F.M.; Hamid, R. Synthesis of nano cementitious additives from agricultural wastes for the production of sustainable concrete. J. Clean. Prod. 2018, 171, 1150-1160. [CrossRef]

83. Muthukrishnan, S.; Gupta, S.; Kua, H.W. Application of rice husk biochar and thermally treated low silica rice husk ash to improve physical properties of cement mortar. Theor. Appl. Fract. Mech. 2019, 104, 102376. [CrossRef]

84. Matos, A.M.; Sousa-Coutinho, J. Durability of mortar using waste glass powder as cement replacement. Constr. Build. Mater. 2012, 36, 205-215. [CrossRef] 
85. Calmon, J.L.; Sauer, A.S.; Vieira, G.L.; Teixeira, J.E.S.L. Effects of windshield waste glass on the properties of structural repair mortars. Cem. Concr. Compos. 2014, 53, 88-96. [CrossRef]

86. Mirzahosseini, M.; Riding, K.A. Effect of curing temperature and glass type on the pozzolanic reactivity of glass powder. Cem. Concr. Res. 2014, 58, 103-111. [CrossRef]

87. Zanwar, A.B.; Patil, Y.D. Enhancement of Sustainable Mortar by Using Fine Glass Powder. In Lecture Notes in Civil Engineering; Shukla, S.K., Barai, S., Mehta, A., Eds.; Springer: Singapore, 2020; Volume 35, pp. 65-72, ISBN 9789811374807.

88. Patel, D.; Tiwari, R.P.; Shrivastava, R.; Yadav, R.K. Effective utilization of waste glass powder as the substitution of cement in making paste and mortar. Constr. Build. Mater. 2019, 199, 406-415. [CrossRef]

89. Khotbehsara, M.M.; Mohseni, E.; Yazdi, M.A.; Sarker, P.; Ranjbar, M.M. Effect of nano-CuO and fly ash on the properties of self-compacting mortar. Constr. Build. Mater. 2015, 94, 758-766. [CrossRef]

90. Chindaprasirt, P.; Rukzon, S. Strength and chloride resistance of the blended Portland cement mortar containing rice husk ash and ground river sand. Mater. Struct. 2015, 48, 3771-3777. [CrossRef]

91. Scheetz, B.E.; Earle, R. Utilization of fly ash. Curr. Opin. Solid State Mater. Sci. 1998, 3, 510-520. [CrossRef]

92. Jow, J.; Dong, Y.; Zhao, Y.; Ding, S.; Li, Q. Fly Ash-based Technologies and Value-added Products Based on Materials Science. In Proceedings of the 2015 World of Coal Ash (WOCA) Conference, Nashville, TN, USA, 5-7 May 2015.

93. NETL (National Energy Technology Laboratory). American Coal Ash Association 2012 Coal Combustion Product Report. Available online: https:/www.netl.doe.gov/research/Coal/energy-systems/gasification/ gasifipedia/solid-waste-bg (accessed on 22 February 2020).

94. Lima, A.T.; Ottosen, L.M.; Ribeiro, A.B. Assessing fly ash treatment: Remediation and stabilization of heavy metals. J. Environ. Manag. 2012, 95, 110-115. [CrossRef]

95. Yin, K.; Ahamed, A.; Lisak, G. Environmental perspectives of recycling various combustion ashes in cement production-A review. Waste Manag. 2018, 78, 401-416. [CrossRef]

96. Siriruang, C.; Toochinda, P.; Julnipitawong, P.; Tangtermsirikul, S. $\mathrm{CO}_{2}$ capture using fly ash from coal fired power plant and applications of $\mathrm{CO}_{2}$-captured fly ash as a mineral admixture for concrete. J. Environ. Manag. 2016, 170, 70-78. [CrossRef]

97. Beltrán, M.G.; Barbudo, A.; Agrela, F.; Jiménez, J.R.; de Brito, J. Mechanical performance of bedding mortars made with olive biomass bottom ash. Constr. Build. Mater. 2016, 112, 699-707. [CrossRef]

98. Yin, K.; Chan, W.-P.; Dou, X.; Lisak, G.; Chang, V.W.-C. Co-complexation effects during incineration bottom ash leaching via comparison of measurements and geochemical modeling. J. Clean. Prod. 2018, 189, 155-168. [CrossRef]

99. Ban, C.C.; Ramli, M. The implementation of wood waste ash as a partial cement replacement material in the production of structural grade concrete and mortar: An overview. Resour. Conserv. Recycl. 2011, 55, 669-685.

100. Paris, J.M.; Roessler, J.G.; Ferraro, C.C.; DeFord, H.D.; Townsend, T.G. A review of waste products utilized as supplements to Portland cement in concrete. J. Clean. Prod. 2016, 121, 1-18. [CrossRef]

101. Rao, G.A. Investigations on the performance of silica fume-incorporated cement pastes and mortars. Cem. Concr. Res. 2003, 33, 1765-1770. [CrossRef]

102. Zhang, T.; Yu, Q.; Wei, J.; Li, J.; Zhang, P. Preparation of high performance blended cements and reclamation of iron concentrate from basic oxygen furnace steel slag. Resour. Conserv. Recycl. 2011, 56, 48-55. [CrossRef]

103. Van Oss, H.G. Iron and Steel Slag. In Mineral Commodity Summaries; U.S. Geological Survey: Reston, VI, USA, 2015; pp. 82-83.

104. Zhang, T.; Gao, P.; Gao, P.; Wei, J.; Yu, Q. Effectiveness of novel and traditional methods to incorporate industrial wastes in cementitious materials-An overview. Resour. Conserv. Recycl. 2013, 74, 134-143. [CrossRef]

105. Rashad, A.M. An overview on rheology, mechanical properties and durability of high- volume slag used as a cement replacement in paste, mortar and concrete. Constr. Build. Mater. 2018, 187, 89-117. [CrossRef]

106. Willett, J.C.; Neely, P.R. Stone, Crushed [Advance Release]. In 2014 Minerals Yearbook; U.S. Geological Survey: Leiston, VA, USA, 2016; pp. 71.1-71.24.

107. Elgalhud, A.A.; Dhir, R.K.; Ghataora, G. Limestone addition effects on concrete porosity. Cem. Concr. Compos. 2016, 72, 222-234. [CrossRef]

108. Siddique, R. Effect of volcanic ash on the properties of cement paste and mortar. Resour. Conserv. Recycl. 2011, 56, 66-70. [CrossRef] 
109. Masmoudi, R.; Kupwade-Patil, K.; Bumajdad, A.; Büyüköztürk, O. In situ Raman studies on cement paste prepared with natural pozzolanic volcanic ash and Ordinary Portland Cement. Constr. Build. Mater. 2017, 148, 444-454. [CrossRef]

110. Zeyad, A.M.; Megat Johari, M.A.; Tayeh, B.A.; Yusuf, M.O. Pozzolanic reactivity of ultrafine palm oil fuel ash waste on strength and durability performances of high strength concrete. J. Clean. Prod. 2017, 144, 511-522. [CrossRef]

111. Noorvand, H.; Ali, A.A.A.; Demirboga, R.; Noorvand, H.; Farzadnia, N. Physical and chemical characteristics of unground palm oil fuel ash cement mortars with nanosilica. Constr. Build. Mater. 2013, 48, 1104-1113. [CrossRef]

112. USDA (United States Department of Agriculture). Rice Yearbook; USDA Economic Research Service: Washington, DC, USA, 2017.

113. Gowda, M.R.; Narasimhan, M.C.; Karisiddappa. Development and study of the strength of self-compacting mortar mixes using local materials. J. Mater. Civ. Eng. 2011, 23, 526-532. [CrossRef]

114. Jani, Y.; Hogland, W. Waste glass in the production of cement and concrete-A review. J. Environ. Chem. Eng. 2014, 2, 1767-1775. [CrossRef]

115. Mirzahosseini, M.; Riding, K.A. Effect of combined glass particles on hydration in cementitious systems. J. Mater. Civ. Eng. 2015, 27, 1-13. [CrossRef]

116. Kim, S.; Hanif, A.; Jang, I. Incorporating liquid crystal display (LCD) glass waste as supplementary cementing material (SCM) in cement mortars-Rationale based on hydration, durability, and pore characteristics. Materials 2018, 11, 2538. [CrossRef]

117. ASTM C618-15. Standard Specification for Coal Fly Ash and Raw or Calcined Natural Pozzolan for Use in Concrete; ASTM International: West Conshohocken, PA, USA, 2015.

118. Taha, B.; Nounu, G. Using lithium nitrate and pozzolanic glass powder in concrete as ASR suppressors. Cem. Concr. Compos. 2008, 30, 497-505. [CrossRef]

119. Dodson, V.H. Concrete Admixtures; Springer Science+Business Media: New York City, NY, USA, 1990; ISBN 978-1-4757-4845-1.

120. Roussel, N.; Lemaître, A.; Flatt, R.J.; Coussot, P. Steady state flow of cement suspensions: A micromechanical state of the art. Cem. Concr. Res. 2010, 40,77-84. [CrossRef]

121. Lu, G.; Wang, K.; Rudolphi, T.J. Modeling rheological behavior of highly flowable mortar using concepts of particle and fluid mechanics. Cem. Concr. Compos. 2008, 30,1-12. [CrossRef]

122. Wang, D.; Shi, C.; Wu, Z.; Xiao, J.; Huang, Z.; Fang, Z. A review on ultra high performance concrete: Part II. Hydration, microstructure and properties. Constr. Build. Mater. 2015, 96, 368-377. [CrossRef]

123. Safiuddin, M.; West, J.S.; Soudki, K.A. Self-Consolidating High Performance Concrete with Rice Husk Ash: Components, Properties and Mixture Design; VDM Publishing House Ltd.: Saarbrücken, Germany, 2009; ISBN 978-3-639-14506-9.

124. Shen, L.; Struble, L.; Lange, D. Modeling dynamic segregation of self-consolidating concrete. ACI Mater. J. 2009, 106, 375-380.

125. Flatt, R.J. Dispersion forces in cement suspensions. Cem. Concr. Res. 2004, 34, 399-408. [CrossRef]

126. Flatt, R.J.; Bowen, P. Electrostatic repulsion between particles in cement suspensions: Domain of validity of linearized Poisson-Boltzmann equation for nonideal electrolytes. Cem. Concr. Res. 2003, 33, 781-791. [CrossRef]

127. Maheswaran, S.; Iyer, N.R.; Palani, G.S.; Pandi, R.A.; Dikar, D.D.; Kalaiselvam, S. Effect of high temperature on the properties of ternary blended cement pastes and mortars. J. Therm. Anal. Calorim. 2015, 122, 775-786. [CrossRef]

128. Wang, X.Y.; Lee, H.S. Simulation of a temperature rise in concrete incorporating fly ash or slag. Mater. Struct. 2010, 43, 737-754. [CrossRef]

129. Narmluk, M.; Nawa, T. Effect of fly ash on the kinetics of Portland cement hydration at different curing temperatures. Cem. Concr. Res. 2011, 41, 579-589. [CrossRef]

130. Lawrence, P.; Cyr, M.; Ringot, E. Mineral admixtures in mortars: Effect of inert materials on short-term hydration. Cem. Concr. Res. 2003, 33, 1939-1947. [CrossRef]

131. ACI 222R-01. Protection of Metals in Concrete against Corrosion (Reapproved 2010); American Concrete Institute (ACI): Farmington Hills, MI, USA, 2011.

132. Young, J.F. Cement-based materials. Curr. Opin. Solid State Mater. Sci. 1998, 3, 505-509. [CrossRef] 
133. Kwan, A.K.H.; Li, Y. Effects of fly ash microsphere on rheology, adhesiveness and strength of mortar. Constr. Build. Mater. 2013, 42, 137-145. [CrossRef]

134. Tudjono, S.; Purwanto Apsari, K.T. Study the effect of adding nano fly ash and nano lime to compressive strength of mortar. Procedia Eng. 2014, 95, 426-432. [CrossRef]

135. Li, Y.; Kwan, A.K.H. Ternary blending of cement with fly ash microsphere and condensed silica fume to improve the performance of mortar. Cem. Concr. Compos. 2014, 49, 26-35. [CrossRef]

136. Shannag, M.J.; Mourad, S.M. Flowable high strength cementitious matrices for ferrocement applications. Constr. Build. Mater. 2012, 36, 933-939. [CrossRef]

137. Sanjuán, M.Á.; Argiz, C.; Gálvez, J.C.; Moragues, A. Effect of silica fume fineness on the improvement of Portland cement strength performance. Constr. Build. Mater. 2015, 96, 55-64. [CrossRef]

138. Benabed, B.; Kenai, S.; Azzouz, L.; Kadri, E.H.; Belaidi, A.S.E. Effects of limestone quarry dust content on rheology and strength of self-compacting mortar. In Proceedings of the Twelfth International Conference on Recent Advances in Concrete Technology and Sustainability Issues, Prague, Czech Republic, 30 October-2 November 2012; pp. 377-388.

139. Kwan, A.K.H.; McKinley, M. Effects of limestone fines on water film thickness, paste film thickness and performance of mortar. Powder Technol. 2014, 261, 33-41. [CrossRef]

140. Ramezanianpour, A.M.; Hooton, R.D. A study on hydration, compressive strength, and porosity of Portland-limestone cement mixes containing SCMs. Cem. Concr. Compos. 2014, 51, 1-13. [CrossRef]

141. Yerramala, A.; Ramachandurdu, C.; Bhaskar Desai, V. Flexural strength of metakaolin ferrocement. Compos. Part B Eng. 2013, 55, 176-183. [CrossRef]

142. Yerramala, A.; Rama Chandurdu, C.; Bhaskar Desai, V. Impact strength of metakaolin ferrocement. Mater. Struct. 2014, 49, 5-15. [CrossRef]

143. Kostuch, J.A.; Walter, G.V.; Jones, T.R. High performance concretes containing Metakaolin-A review. In Proceedings of the Concrete 2000: Economic and Durable Construction through Excellence, Dundee, Scotland, 7-9 September 1993; pp. 1799-1811.

144. Taylor-Lange, S.C.; Riding, K.A.; Juenger, M.C.G. Increasing the reactivity of metakaolin-cement blends using zinc oxide. Cem. Concr. Compos. 2012, 34, 835-847. [CrossRef]

145. Morsy, M.S.; Al-Salloum, Y.A.; Abbas, H.; Alsayed, S.H. Behavior of blended cement mortars containing nano-metakaolin at elevated temperatures. Constr. Build. Mater. 2012, 35, 900-905. [CrossRef]

146. Argiz, C.; Menéndez, E.; Moragues, A. Advances in coal bottom ash use as a new common Portland cement constituent. In Service Life and Durability of Reinforced Concrete Structures: Selected Papers of the 8th International RILEM PhD Workshop held in Marne-la-Vallée, France, 26-27 September 2016; Andrade, C., Gulikers, J., Marie-Victoire, E., Eds.; Springer: Cham, Switzerland, 2019; Volume 17, pp. 43-53, ISBN 978-3-319-90236-4.

147. Yao, Y.; Sun, H. Durability and leaching analysis of a cementitious material composed of high volume coal combustion byproducts. Constr. Build. Mater. 2012, 36, 97-103. [CrossRef]

148. Hossack, A.M.; Thomas, M.D.A. Varying fly ash and slag contents in Portland limestone cement mortars exposed to external sulfates. Constr. Build. Mater. 2015, 78, 333-341. [CrossRef]

149. Hossack, A.M.; Thomas, M.D.A. Evaluation of the effect of tricalcium aluminate content on the severity of sulfate attack in Portland cement and Portland limestone cement mortars. Cem. Concr. Compos. 2015, 56, 115-120. [CrossRef]

150. Li, L.G.; Zhu, J.; Huang, Z.H.; Kwan, A.K.H.; Li, L.J. Combined effects of micro-silica and nano-silica on durability of mortar. Constr. Build. Mater. 2017, 157, 337-347. [CrossRef]

151. Mlinarik, L.; Kopecskó, K. The influence of combined application of two SCMs on the corrosion and acid attack durability of mortars. Period. Polytech. Civ. Eng. 2016, 61, 313-321. [CrossRef]

152. Matos, A.M.; Sousa-Coutinho, J. ASR and sulphate performance of mortar containing industrial waste. Struct. Concr. 2016, 17, 84-95. [CrossRef]

153. Siddique, R.; Bennacer, R. Use of iron and steel industry by-product (GGBS) in cement paste and mortar. Resour. Conserv. Recycl. 2012, 69, 29-34. [CrossRef]

154. Hadj-sadok, A.; Kenai, S.; Courard, L.; Darimont, A. Microstructure and durability of mortars modified with medium active blast furnace slag. Constr. Build. Mater. 2011, 25, 1018-1025. [CrossRef]

155. Torres, S.M.; Sharp, J.H.; Swamy, R.N.; Lynsdale, C.J.; Huntley, S.A. Long term durability of Portland-limestone cement mortars exposed to magnesium sulfate attack. Cem. Concr. Compos. 2003, 25, 947-954. [CrossRef] 
156. Yazıc1, Ş.; Arel, H.Ş.; Anuk, D. Influences of metakaolin on the durability and mechanical properties of mortars. Arab. J. Sci. Eng. 2014, 39, 8585-8592. [CrossRef]

157. Bamaga, S.O.; Hussin, M.W.; Ismail, M.A. Palm Oil Fuel Ash: Promising supplementary cementing materials. KSCE J. Civ. Eng. 2013, 17, 1708-1713. [CrossRef]

158. Chatveera, B.; Lertwattanaruk, P. Evaluation of sulfate resistance of cement mortars containing black rice husk ash. J. Environ. Manag. 2009, 90, 1435-1441. [CrossRef]

159. ASTM C1437-15. Standard Test Method for Flow of Hydraulic Cement Mortar; ASTM International: West Conshohocken, PA, USA, 2015.

160. Sakir, S.; Raman, S.N.; Kaish, A.B.M.A.; Mutalib, A.A. Self-flowing mortar for ferrocement in strengthening applications. Perspect. Sci. 2016, 8, 673-676. [CrossRef]

161. Phua, Z.; Giannis, A.; Dong, Z.L.; Lisak, G.; Ng, W.J. Characteristics of incineration ash for sustainable treatment and reutilization. Environ. Sci. Pollut. Res. 2019, 26, 16974-16997. [CrossRef]

162. ASTM C33/C33M-16e1. Standard Specification for Concrete Aggregates; ASTM International: West Conshohocken, PA, USA, 2016.

163. Hunger, M.; Brouwers, H.J.H. Flow analysis of water-powder mixtures: Application to specific surface area and shape factor. Cem. Concr. Compos. 2009, 31, 39-59. [CrossRef]

164. Kwan, A.K.H.; Fung, W.W.S.; Wong, H.H.C. Water film thickness, flowability and rheology of cement-sand mortar. Adv. Cem. Res. 2010, 22, 3-14. [CrossRef]

165. Aïtcin, P.C. Cements of yesterday and today - concrete of tomorrow. Cem. Concr. Res. 2000, 30, 1349-1359. [CrossRef]

166. Holland, T.C. Silica Fume User's Manual; Federal Highway Administration, U.S. Department of Transportation \& Silica Fume Association: Washington, DC, USA, 2005.

167. LNEC E-462. Resistance of Cements to Sulphate Attack; National Laboratory of Civil Engineering: Lisbon, Portugal, 2004.

168. ASTM C1202-17. Standard Test Method for Electrical Indication of Concrete's Ability to Resist Chloride Ion Penetration; ASTM International: West Conshohocken, PA, USA, 2017.

169. ASTM C1567-13. Standard Test Method for Determining the Potential Alkali-Silica Reactivity of Combinations of Cementitious Materials and Aggregate (Accelerated Mortar-Bar Method); ASTM International: West Conshohocken, PA, USA, 2013.

170. CEB-FIP. Diagnosis and Assessment of Concrete Structures-State-of-Art Report; FIB-International Federation for Structural Concrete: Lausanne, Switzerland, 1989.

171. Irassar, E.F. Sulfate attack on cementitious materials containing limestone filler-A review. Cem. Concr. Res. 2009, 39, 241-254. [CrossRef]

172. Jamil, M.; Kaish, A.B.M.A.; Raman, S.N.; Zain, M.F.M. Pozzolanic contribution of rice husk ash in cementitious system. Constr. Build. Mater. 2013, 47, 588-593. [CrossRef]

173. Mirzahosseini, M.; Riding, K.A. Influence of different particle sizes on reactivity of finely ground glass as supplementary cementitious material (SCM). Cem. Concr. Compos. 2015, 56, 95-105. [CrossRef]

174. Leese, R.; Casey, D. Embodied CO2e of UK Cement, Additions and Cementitious Material; MPA Cement, Mineral Products Association (MPA): London, UK; Available online: https:/cement.mineralproducts.org/documents/ Factsheet_18.pdf (accessed on 24 March 2020).

175. BS 8500-1:2006. Concrete-Complementary British Standard to BS EN 206-1-Part 1: Method of Specifying and Guidance for the Specifier; British Standards Institution: London, UK, 2006; p. 38.

(C) 2020 by the authors. Licensee MDPI, Basel, Switzerland. This article is an open access article distributed under the terms and conditions of the Creative Commons Attribution (CC BY) license (http://creativecommons.org/licenses/by/4.0/). 